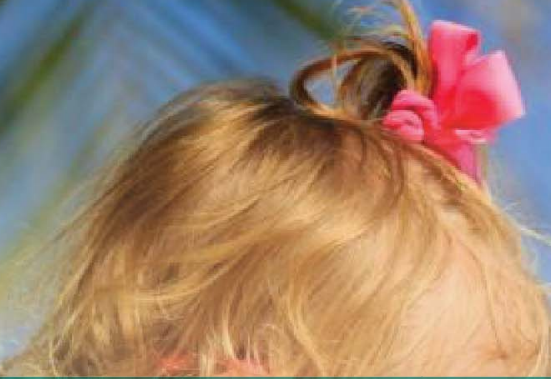

Abdul Kader Mohiuddin

World University of Bangladesh, Bangladesh

e-Book

SUBJEGTS: PHARMRHEOLOGY

Peertechz

2
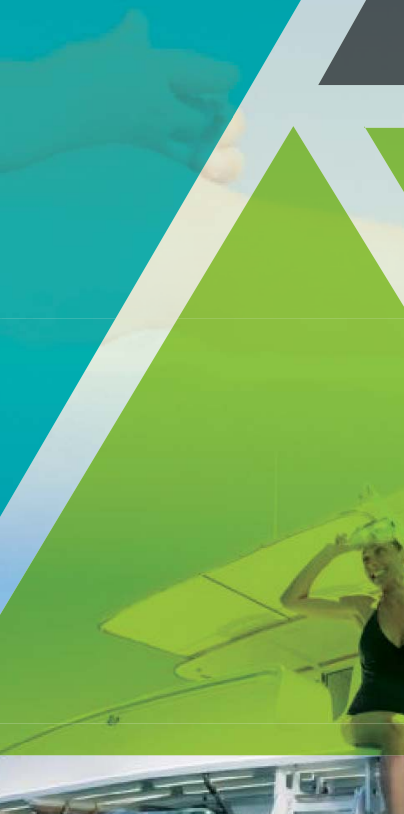

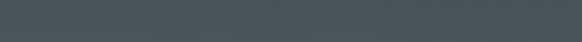

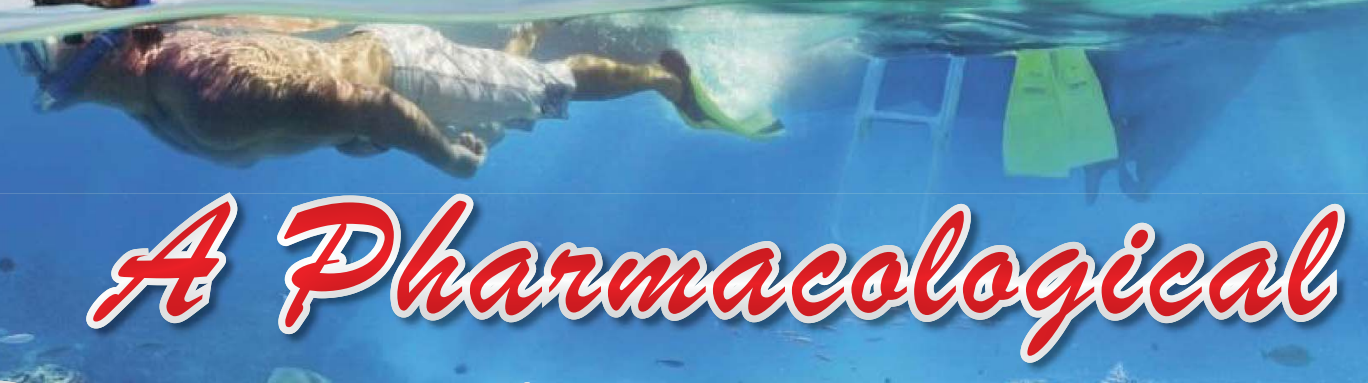

Pericen of Smacenen and

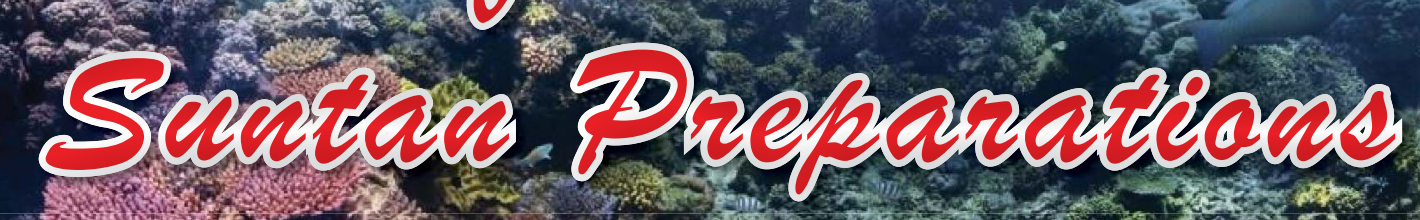

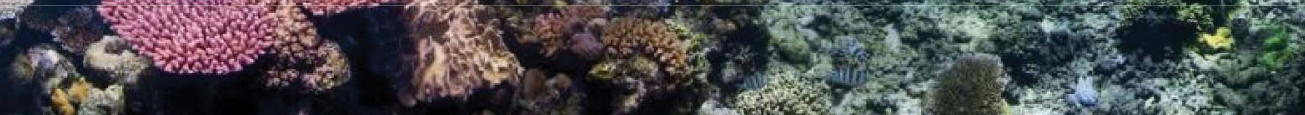
1.2. . 9,3

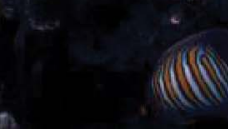
is 3 ,

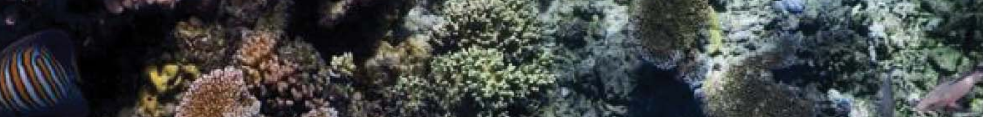
$4+6$ - 6 . are 213 (x) 


\section{Published by Peertechz Publications}

Title: A Pharmacological Review of Sunscreen and Suntan Preparations

Subjects: Pharmacology

Received: 31-05-2019

Accepted: 31-08-2019

Published: 05-08-2019

*Corresponding author: Abdul Kader Mohiuddin, Department of Pharmacy, World University of Bangladesh, 151/8, Green Road, Dhanmondi, Dhaka - 1205, Bangladesh,Tel: +8801716477485; Email: mohiuddin3@pharmacy.wub.edu.bd

ISBN: 978-81-943057-1-2

DOI: 10.17352/ebook10112 


\section{Table of Contents}

\begin{tabular}{r|l}
004 & 1. Summary \\
005 & 2. Abbreviations \\
006 & 3. Background \\
$007-008$ & 4. Introduction \\
\hline $009-021$ & 5. Sunburn \\
\hline $022-023$ & 6. Classifi cation of Sunscreens \\
\hline $024-030$ & 7. FDA approved sunscreen ingredients: Literature Review \\
\hline $031-033$ & 8. Sunscreen Formulation \\
\hline $034-035$ & 9. Sunscreen vs Coral Reef \\
\hline 036 & 10. Article Summary \\
\hline $037-043$ & $\mathbf{1 1 . ~ R e f e r e n c e s}$
\end{tabular}




\section{Summary}

The sunscreen industry is achieving remarkable worldwide prominence by responding to the growing need for skin protection with fast-paced innovation. Increased consumer awareness of the harmful effects of sunlight has fueled the demand for improved photo protection. The need for broad-spectrum protection from both UVA and UVB rays has inspired scientists worldwide to research new cosmetic formulations and delivery systems. More effective sunscreen actives, emollients and novel cosmetic and functional ingredients have been regularly added to the formulator's repertoire. Creativity in innovation has been hindered only by regulatory agencies and patent restrictions worldwide. Familiarity with the current restrictive regulations and patent law infringements has become integral to any research effort attempting to provide improved protection to individuals affected by the sun's damaging effects. The increasing incidence of skin cancers and photo damaging effects caused by ultraviolet radiation has increased the use of sun screening agents, which have shown beneficial effects in reducing the symptoms and reoccurrence of these problems. Unlike the situation in Europe where sunscreen ingredients are considered under cosmetics guidelines, the FDA is required to define sunscreens as drugs since they are advertised to prevent sunburn and, more recently, the risk of skin cancer. In the USA, the FDA has been regulating this industry since August 25,1978, with the publication of the Advance Notice of Proposed Rulemaking. Sunscreens are considered drugs and cosmetics and therefore must be governed by the FDA-OTC monograph. With the variety of sunscreen agents used in cosmetic and UV protection products, Australia, Canada, and the European Union (EU)

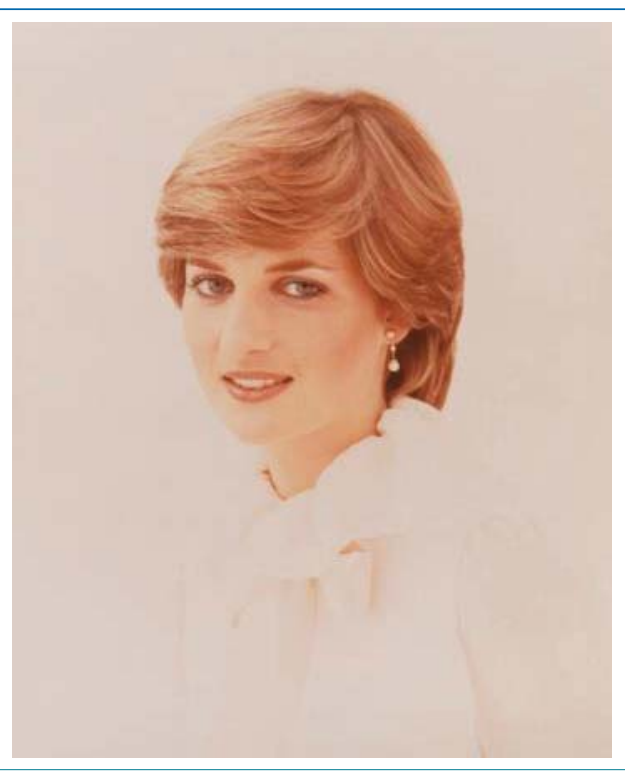

Figure 1: Diana, Princess of Wales, Vogue 1981. According to the magazine Longevity, Princess Diana was "scrupulous about using an SPF-8 sunblock." While the American Academy of Dermatology recommends applying at least SPF 30, protection against UV rays can prevent both sunburn and dangerous skin cancers (Source: Picard C. 25 Beauty Secrets to Steal from Princess Diana. Web GoodHousekeeping.com, Mar 7, 2017). have also developed regulatory protocols on safe sunscreen product use. Unlike the USA though, Australia has approved 34 active sunscreen ingredients and the EU has approved 28 of these ingredients. Current FDA regulations allow labeling of sunscreen products to a maximum of $30 \mathrm{p}$, despite the many products currently available with numbers as high as 100. From a cosmetic formulation point of view, increasing the SPF number in a product is governed by simple chemical principles (Figure 1). 


\section{Abbreviations}

NMSC: Non-Melanoma Skin Cancer; KLF4: Kruppel Like Factor 4; PPARG: Peroxisome Proliferator Activated Receptor Gamma; APC: Antigen Presenting Cell; BBB: Blood-Brain Barrier; EWG: Environmental Working Group; GRASE: Generally Recognized As Safe And Effective; PABA: P-Aminobenzoic Acid; MSs: Mesoporous Silicas; HPCD: HydroxyPropyl-beta-CycloDextrin; OMC: Octyl Methoxycinnamate; ROS: Reactive Oxygen Species; PUVA: Psoralen plus UVA; SAD: Seasonal Affective Disorder; MDD: Major Depressive Disorder; AK: Actinic Keratosis; SCC: Squamous Cell Carcinoma; BCC: Basal Cell Carcinoma; NPs: Polymeric Nanoparticles; BEMT: Bisethylhexyloxyphenol Methoxyphenyl Triazine; SLN: Solid Lipid Nanoparticle; HDPE/LDPE: High-Density Polyethylene/Low-Density Polyethylene; EAE: Autoimmune Encephalomyelitis; MS: Multiple Sclerosis; iNOS: Inducible Nitric Oxide Synthase; TNF- $\alpha$ : Tumor Necrosis Factor Alpha; IARC: International Agency for Research on Cancer; UV: Ultraviolet; UVAPF: A Protection Factor 


\section{Background}

$\mathrm{Ra}(\mathrm{Re})$ was the primary name of the sun god of Ancient Egypt. According to Osiris myth, Nut, the mother of Osiris swallowed the setting sun ( $\mathrm{Ra}$ ) each evening and gave birth to him each morning. The Ancient Egyptians were well aware of the dangers of the sun. Their lands were scorched with heat. Women protected their skin, preferring light skin to dark in their cultural hierarchy of beauty. Recent discoveries written on papyri and the walls of several tombs unearthed ingredients and formulations in use in Ancient Egypt specifically addressing issues of sun damage to the hair and skin. Also, a brief historical review manifests the following interesting things indeed:Jasmin was used to heal the sun-damaged skin. Recent evidence reveals that Jasmin aids in DNA repair at the cellular level.

- Aloe was used to heal sun-damaged skin.

- Olive oil was used as a hydrating oil for both skin and hair damaged by overexposure to the sunlight.

- Almond oil was applied before and after sun exposure to hydrate the sun-damaged skin, improving elasticity and texture.

- Rice bran extracts were used in sunscreen preparations. Today, gamma oryzanol extracted from rice bran has UV absorbing properties.

- kohl (to darken eyes in order to combat sunlight impairment to the retina in the glare of the desert sun), red ochre (to redden and impart a rosy glow in women's makeup mimicking the effect of the sun on the skin), and henna oil (to dye the lips and nails, darken the color of the hair and skin, and protect light skin from the sun). Today, henna is one of the most widely used natural sunscreen with both UVA and UVB protection.

- Lupin extract was used to block the rays of the sun and is still used to date to lighten the color of the skin.

- Calcite powder and clay were used as UV filters similar to the modern-day inorganic particulates zinc oxide and titanium dioxide.

- Aquatic lotus oil was used for protection of the skin from the sun. 


\section{Introduction}

Protection from sunlight is often equated with use of sunscreens, but this approach is too narrow, and protection should consist of a package of measures: avoiding overexposure to sunlight, using sunscreens, and wearing protective clothing. Solar ultraviolet (UV) radiation significantly influences the skin, causing aging, sunburns, precancerous and cancerous lesions, and immunosuppression. UV radiation has an immunosuppressive effect on the antigen-presenting cells within the epidermis and contributes to the likelihood of skin cancer. If solar radiation is a primary risk factor for malignant melanoma, it is reasonable to conclude that reducing sun exposure via topical sunscreen use would be associated with reduced disease risk. Melanoma is more common in Whites than in Blacks and Asians. The incidence of non-melanoma skin cancer (NMSC) is dramatically increasing worldwide, despite the increased use of improved sunscreens. In 2014, the Surgeon General estimated that 2.2-5.0 million people were treated annually for NMSC. As the number of newly diagnosed skin cancers continues to rise, there is a need for additional preventative measures beyond sunscreens. UV radiation is the second most prevalent carcinogenic exposure in Canada, fifth in Switzerland and is similarly important in other countries with large Caucasian populations. Within the UK, Wales has among the highest rates of skin cancer annually and skin cancer diagnosis rates have increased 63\% in 10 years. Australia and New Zealand having the world's highest skin cancers. People living in Australia and New Zealand are now advised to apply sunscreen every day when the UV index is predicted to reach 3 or above. Denmark has one of the highest incidences of melanoma in the world, although it is a relatively northern country. Implications for public health: Increased use of sunscreen as part of the daily routine to reduce incidental sun exposure will lead to decreased incidence of skin cancer in the future. There are 3 kinds of UV radiation: UVC, UVB, and UVA. The ozone layer ingests $100 \%$ of UVC, $90 \%$ of UVB, and a negligible measure of UVA. Therefore, exhaustion of the ozone layer expands UV transmission. UVA is related with aging and pigmentation. It enters profound into the skin layer and creates free extreme oxygen species, in a roundabout way damaging DNA. UVA expands the quantity of incendiary cells in the dermis and diminishes the quantity of antigens introducing cells. UVB causes sunburn and DNA strand breaks. It causes pyrimidine dimer changes which are related with non-melanoma skin malignancies. Photoprotection includes both essential and secondary protective variables. Essential variables are sunscreens; these incorporate physical barriers which reflect and dissipate light, and substance barriers which ingest light. Secondary components incorporate cancer prevention agents, osmolytes, and DNA repair enzymes which help to constrain skin harm by exasperating the photochemical cascade that happens by UV sunlight. People with black skin are much less susceptible to sunburn than white-skinned individuals. Black people living in the UK were more likely to use sunscreen as a form of sun protection, whereas sunscreen was the least popular modality in the two African countries with shade being the most common form of limiting sun exposure. A significant benefit from regular sunscreen use has not yet been demonstrated for primary prevention of basal cell carcinoma and melanoma. Concerning the prevention of actinic keratoses, squamous cell carcinomas, and skin aging, the effect of sunscreens is significant, but it remains incomplete. Some organic UV filters (PABA derivatives, cinnamates, benzophenones, and octocrylene) have been described to cause photo allergy. Percutaneous absorption and endocrine disrupting activity of small-sized organic and nano-sized inorganic UV filters have been reported. 


\section{Positive Effects of UVR}

Exposure to UVR is not always considered bad. In fact, UVR has been found to be particularly helpful in treating vitamin D deficiency, seasonal affective disorders, psoriasis, sarcoidosis, mycosis fungoides, and numerous other cutaneous conditions. Within the epidermis, 7-dehydrocholesterol is converted to vitamin D (cholecalciferol) by UVB light. The elderly and young children are the ones who are particularly susceptible to vitamin D deficiency. Vitamin D deficiency can lead to rickets in children, osteomalacia in adults, osteopenia/osteoporosis, and factures in the elderly. The Institute of Medicine recommends the following vitamin D allowances: $400 \mathrm{IU}$ for 0 to 12 months, $600 \mathrm{IU}$ for 1 to 70 years, and $800 \mathrm{IU}$ for greater than 70 years. Light therapy is an inexpensive treatment and can be beneficial in treating certain diseases. Although it has been known for the last 100 years that UV light (particularly UVC with a wavelength range of $240-280 \mathrm{~nm}$ ) is highly germicidal, its use to treat wound or other localized infections remains at an early stage of development. Candida auris is a globally emerging yeast, causing severe infections in patients with underlying diseases. This yeast is responsible for several outbreaks within healthcare facilities, where it can be found on hospital surfaces and patient care devices. Spread from these fomites may be prevented by improving the decontamination of hospital surfaces. UV-C decontamination may constitute an effective adjunct to routine room cleaning. Additionally, difficult-to-treat psoriasis patients sometimes find relief with UVR. It is thought that UVR has both antiproliferative and anti-inflammatory effects through downregulation of T-cell response to antigens. Studies have also shown improvement of the cutaneous effects of sarcoidosis with UVA-1 light and topical psoralen plus UVA (PUVA) therapy. PUVA and narrowband UVB has been shown to induce and maintain remissions of mycosis fungoides. Phototherapy is the use of light for reducing the concentration of bilirubin in the body of infants. However, the exposure to UV in childhood has been established as an important contributing factor for melanoma risk in adults and considering the high susceptibility to UV-induced skin damage of the newborn, related to his pigmentary traits, the UV exposure of the infant during phototherapy should be "as low as reasonably achievable," considering that it is unnecessary to the therapy. Protective eyewear can be necessary during newborn assistance activities carried out in proximity of some sources. Most people judge sun exposure in nonerythemic doses as pleasant. Exposure to sunlight has been linked to improved energy and elevated mood. Seasonal affective disorder (SAD) is a seasonal pattern of recurrent major depressive episodes that most commonly occurs during autumn or winter and remits in spring. The prevalence of SAD ranges from 1.5\% to $9 \%$, depending on latitude. Evidence on light therapy as preventive treatment for patients with a history of SAD is limited, preventive treatment of SAD and the treatment selected should be strongly based on patient preferencesLight therapy, an effective treatment for seasonal affective disorder (SAD), may also be appropriate for MDD which is the second-ranked cause of disability worldwide. Bright light treatment, both as monotherapy and in combination with fluoxetine, was efficacious and well tolerated in the treatment of adults with nonseasonal MDD. The combination treatment had the most consistent effects [1-7]. 


\section{Sunburn}

\section{Sunburn and sunscreen fact}

- Sunburn and sun poisoning are forms of skin damage due to UV ray exposure. The symptoms can range from mild to severe and may require treatment.

- Sunburn might be sun poisoning if there is blisters, hives or rash, fever and chills, nausea, dehydration, headache, pain and tingling, vision problems [8].

- UV rays are most intense at noon and the hours immediately before and after (between 10AM and $4 \mathrm{PM})[9,10]$.

- Immediate symptoms of sunburn are hot, red, tender skin; pain when the skin is touched or rubbed; and dehydration; several days after exposure the skin may swell, blister, and peel [11].

- Most sunburns are mild and can be treated with home remedies such as applying damp cloths or compresses to reduce the pain, soaking in a tepid bath (with no soap), gently patting the skin dry, applying soothing creams or lotions, OTC pain relievers such as Tylenol or others, and moisturizing the skin [12].

- Sunburn may cause permanent skin damage and skin cancer (malignant melanoma, basal cell carcinoma, squamous cell carcinoma) [13].

- Persons with certain pigment disorders and individuals with fair skin are at most risk of sunburn [14].

- Certain diseases and conditions pose a higher risk of sunburn (for example, albinism, lupus, porphyria, vitiligo, and xeroderma pigmentosum) [15].

- Some medications may increase sensitivity to sunburn (photosensitivity) $[10,16]$,

- Sun poisoning is caused by severe sunburn; its symptoms include fever, nausea, chills, dizziness, rapid pulse, rapid breathing, dehydration, and shock [17].

- UVA and UVB are mainly responsible for skin pathologies such as sunburns, cutaneous degeneration, photosensitivity, phototoxicity, photo-aging, immunosuppression and skin cancer [18].

- Snow reflects up to $80 \%$ of the sun's rays, sand reflects $15 \%$, and grass, soil, and water reflect $10 \%$. Due to these factors, an individual sitting under a solitary standard beach umbrella can be exposed to up to $84 \%$ of the total UV radiation despite feeling adequately covered. For these reasons, it is best to seek deep shade [19].

- Less than $50 \%$ of the SPF number claimed on the label is spread on the consumer's skin, meaning that a sunscreen with an SPF 30 will give the real protection of an SPF of 15. Therefore, SPF 60 should 
be recommended if real protection of 30 is desired. Significant injury, DNA damage, mutations, and carcinogenesis can and do occur also with cumulative sub-erythemal UV exposure [20].

- The SPF was created in 1956 by Schulze and it reflects the ratio between the lower amount of UV energy required to produce a minimal erythema on sunscreen protected skin and the amount of energy required to produce the same erythema on unprotected skin [21].

- Since many of UV filters were shown to cross the blood-brain barrier (BBB), the risk for neurotoxicity also occurs [22].Sunscreen compounds might block vitamin D synthesis or act as endocrine disruptor and lead to developmental toxicity. The effects of sunscreen on cutaneous synthesis of vitamin D induced by sunlight have been a subject of debate for recent years, however the newest analysis suggests, that normal usage of sunscreen by adults do not decrease cutaneous synthesis of vitamin $\mathrm{D}[23]$.

- The FDA is notoriously slow in approving sunscreen compounds, requiring exhaustive evidence of their safety. Indeed, FDA has approved only 16 sunscreen ingredients (14 organic filters and two nonorganic filters, including zinc oxide and titanium dioxide), while other areas of the world, like the European Union and Australia, have approved nearly twice as many [24].

- FDA approved sunscreen ingredients are Aminobenzoic acid, Avobenzone, Cinoxate, Dioxybenzone, Homosalate, Meradimate, Octocrylene, Octinoxate, Octisalate, Oxybenzone, Padimate 0, Ensulizole, Sulisobenzone, Titanium dioxide, Trolamine salicylate, Zinc oxide [25].

- Two of the 16 main ingredients used in OTC sunblock products are safe, the FDA said. Moreover, the FDA is requesting more information on 12 ingredients among the 16 [26].

- The FDA has changed its guidelines to address broad-spectrum sunscreen use, which involves UVA and UVB coverage; water resistance, to indicate the time duration the sunscreen is effective; and sun protection factor (SPF). SPF-15 or higher is recommended and can be labeled as reducing the risk of skin cancer and early skin aging [27].

- PABA and trolamine salicylate - are not GRASE for use in sunscreens, are no longer permitted for use in OTC sunscreen products. No sunscreens sold in the United States contain PABA or trolamine salicylate $[28,29]$.

- For a decade, Environmental Working Group (EWG) has worked to raise concerns about sunscreens with oxybenzone, which is found in nearly all Americans, detected in breast milk and potentially causing endocrine disruption [30].

- Hawaii recently enacted legislation that will ban the use of two major ingredients -oxybenzone and octinoxate-that have also been implicated in coral toxicity and will be banned. This creates a healthcare dilemma: Will the protection of coral reefs result in an increase in human skin cancers? [31].

\section{Sunburn: Pathophysiology}

Sunburn is a radiation burn to the skin caused by too much exposure to the sun's UV rays or artificial sources such as tanning beds. Chronic sun exposure creates premature cutaneous aging, decreases immune response to environmental pathogens, and increases the risk for developing premalignant and malignant neoplasms [1]. The biggest risk factors for sunburn is the amount of time the skin is exposed to UV rays, plus the intensity. Many factors such as time of day, medications, ozone depletion, high altitude, clear skies, and skin phototypes influence sunburns [32]. Exposure to solar radiation has the beneficial effects of stimulating the cutaneous synthesis of vitamin D and providing radiant warmth. Unfortunately, when the skin is subjected to excessive radiation in the ultraviolet range, deleterious effects may occur. The most conspicuous is acute 
sunburn or solar erythema. Initially, UVR causes vasodilation of cutaneous blood vessels, resulting in the characteristic erythema. Within 1 hour of UVR exposure, mast cells release preformed mediators including histamine, serotonin, and tumor necrosis factor, leading to prostaglandin and leukotriene synthesis. Within 2 hours after UV exposure, damage to epidermal skin cells is seen. Erythema usually occurs 3-4 hours after exposure, with peak levels at 24 hours [33]. Sunburns are graded as pink, red, and blistering. In contrast, thermal burns are graded by degree (first, second, and third), but this classification should not be applied to sunburns because thermal burns have quite different sequelae, such as scarring and death, which are extremely rare consequences of sunburn. Keratoconjunctivitis or ocular sunburn can also be caused by UV radiation, and it follows a similar time course. Studies have shown that UVA impairs the antigen presenting cell (APC) activity of the epidermal cells and thereby causes immune suppression, thus contributing to the growth of skin cancer [34]. In summary, UVA radiation can cause nuclear and mitochondrial DNA damage, gene mutations and skin cancer, dysregulation of enzymatic chain reactions, immune suppression, lipid peroxidation (membrane damage), and photoallergic and phototoxic effects.

On the molecular level, exposure to UV radiation can result in a covalent joining of pyrimidine (usually thymine) dimers. DNA repair mechanisms, such as nucleotide excision repair, base excision repair, or mismatch repair genes, do not recognize dimers, the mutations go uncorrected to the cell cycle. When mutated genes reach the cell cycle, if not repaired by the induction of the p53 pathway, a series of changes can

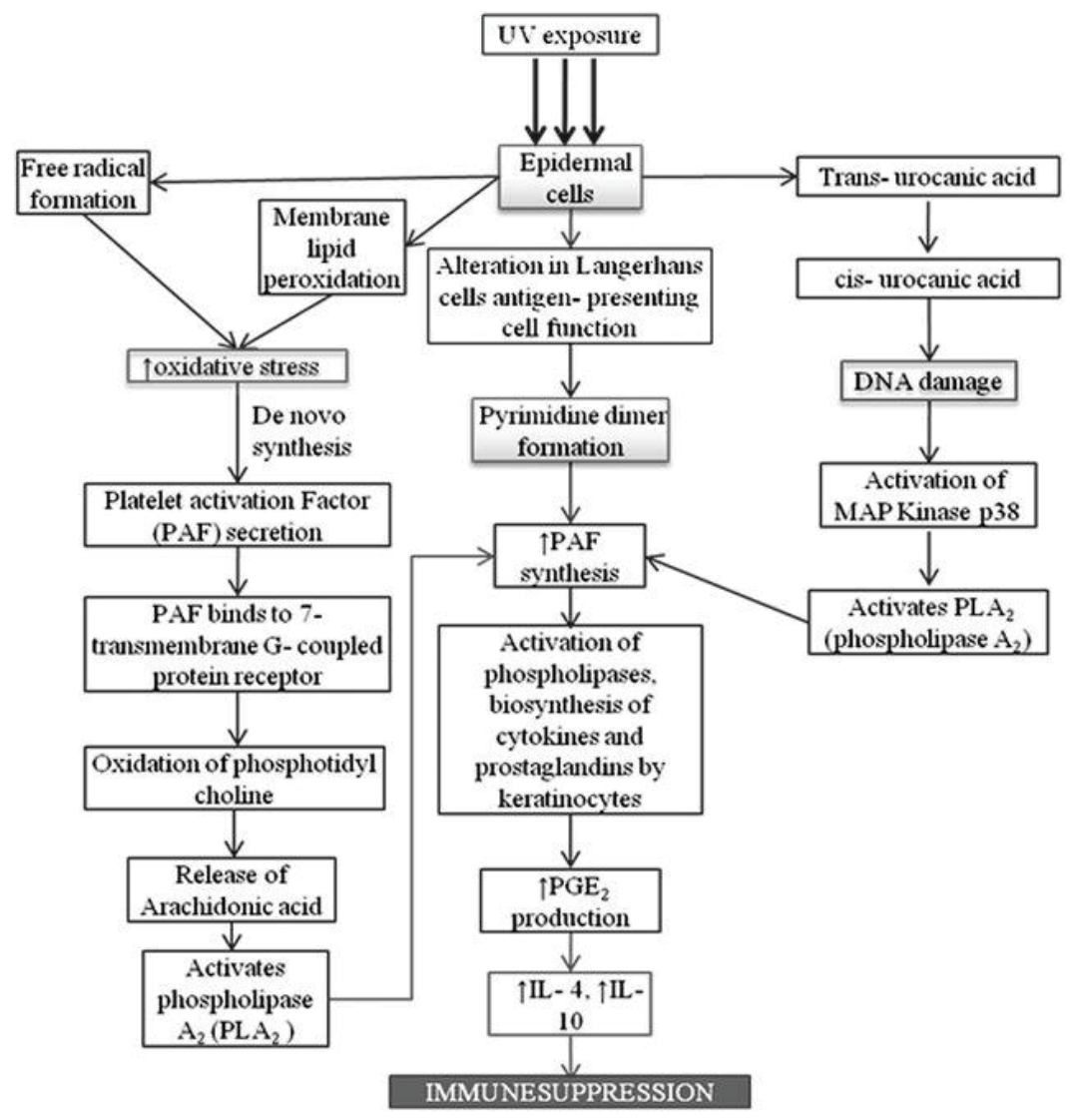

Figure 2: Mechanism of UV induced immunosuppression [130], [139-141]. UVR, in particular the UVB range, suppresses the immune system in several ways. UVB inhibits antigen presentation, induces the release of immunosuppressive cytokines and causes apoptosis of leukocytes. UVB, however, does not cause general immunosuppression but rather inhibits immune reactions in an antigen-specific fashion. Application of contact allergens onto UV-exposed skin does not cause sensitization but induces antigen-specific tolerance since such an individual cannot be sensitized against the very same allergen later, although sensitization against other allergens is not impaired. This specific immunosuppression is mediated by antigen-specific suppressor/ regulatory $\mathrm{T}$ cells. UVB-induced DNA damage is a major molecular trigger of UV-mediated immunosuppression. Reduction of DNA damage mitigates UV-induced immunosuppression. Likewise, interleukin-12 which exhibits the capacity to reduce DNA damage can prevent UV-induced immunosuppression and even break tolerance. Presentation of the antigen by UV-damaged Langerhans cells in the lymph nodes appears to be an essential requirement for the development of regulatory T cells. Studies addressing the molecular mechanisms underlying UV-induced immunosuppression will contribute to a better understanding how $\mathrm{UV}$ acts as a pathogen but on the other hand can be also used as a therapeutic tool. 
result in malignant transformation and immunosupression. UV-induced immunosuppression contributes to skin cancer due to damage to DNA and inhibition of protective mechanism within the skin (Figure 2). A common type of sun-related skin damage is actinic keratosis (AK). Age, Fitzpatrick skin type 1 or 2 (See exhibit 1), and UV light are the major risk factors for developing AK. Most AKs do not progress into invasive squamous cell carcinoma (SCC), but the risk is still present. The risk of malignant transformation of an AK to SCC within one year is approximately 1 in 1,000. However, approximately $60 \%$ of invasive SCCs of the skin probably arise from AKs. If not treated or protected against additional sun damage, AKs may eventually progress to invasive SCC. Avoiding sun exposure and daily application of sunscreen statistically decreases the number of AKs [1] (Figure 2, Exhibit 1).

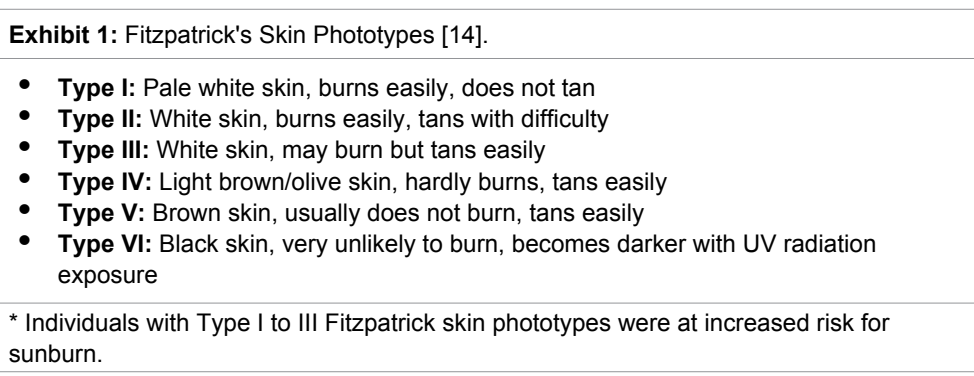

The diagnosis of SCC has increased over the past 30 years. The most important risk factor for SCC is cumulative sun damage and age, the risk was greatest in those with more than 30,000 hours of cumulative lifetime sun exposure. UVA, UVB, PUVA, and tanning beds have been shown to increase the incidence of cutaneous SCC. Prevention of SCC includes protection from the sun, including the use of protective clothing and application of sunscreen. Basal cell carcinoma (BCC) is the most common skin cancer and occurs most frequently on the face and head. In Caucasians, the incidence of BCC has steadily increased and the lifetime risk of developing BCC is $30 \%$ [35]. BCC arises from the basal layer of epidermis and its appendages. The most important risk factor is chronic UVR. Other known risk factors include fair skin, light eyes, red hair, chronic arsenic exposure, therapeutic radiation, immunosuppression, basal cell nevus syndrome, and various other genetic predispositions. Primary prevention is protection from sun exposure beginning at an early age [1]. Other than UVR, exposure to arsenic, radiation, chronic inflammatory conditions in skin, and burns, scars, infections complications or even tattoos are also the contributing factors for BCC [36] (Figure 3).

Epidemiological analysis reveals that annually in the United States alone, $\sim 5$ million skin cancer patients are treated, and that between 40 and $50 \%$ of Americans are susceptible to develop skin cancer at least once by the age of 65 [37]. More than $90 \%$ of melanoma cases in the United States are attributed to skin cell damage from UV radiation exposure. Skin cancer is the most common form of cancer, representing $40-50 \%$ of all cancers diagnosed in the US. Melanoma is the most serious form of skin cancer. Melanoma is responsible for the most skin cancer deaths, with about 9,000 persons dying from it each year [37]. Despite early screening and detection programs, the overall mortality rate from melanoma has remained stable or continues to rise. The incidence of melanoma has more than tripled in the Caucasian population in the United States over the past 30 years. An estimated $60-70 \%$ of cutaneous malignant melanomas are thought to be caused by UV radiation exposure. Two types of UV radiation are primarily responsible for causing carcinogenic skin damage: UVA (315 nm-400 nm) and UVB (280 nm-315 nm) [38]. Intense and intermittent sun exposure at a young age increases a patient's risk of melanoma. Individuals with five or more severe sunburns in childhood or adolescence have an estimated twofold greater risk of developing melanoma. Melanoma is commonly found on areas sporadically exposed to UVR, such as the back of the legs in women and the backs of men. UVB, UVA, and PUVA therapy all have been proven to increase the risk of melanoma. Appropriate UVR protection decreases the risk of developing a melanoma or having a secondary melanoma. Studies indicate that decreasing recreational sun exposure following the diagnosis of primary melanoma can significantly decrease the chance of developing a second melanoma [1] (Exhibit 2).

\section{Photoaging}

Every organ experience aging in various ways. Skin aging can be categorized into three groups, intrinsic, photo, and hormonal aging. The consequences of photo-aging are usually characterized by morphological 
Figure 3: UVB response in melanoma [85]. UVB exposure triggers macrophage and neutrophil infiltration into the skin. Upregulation of CCR2 and ATF2 in melanocytes promotes recruitment of macrophages into the skin, which in turn stimulates production of CCL2, MMP-9, and IFN- $\gamma$ in macrophages. IFN- $\gamma$ signaling from macrophages promotes a positive feedback loop between melanocytes and macrophages, in which melanocytes upregulate CCL8, a CCR2 ligand, and promote further recruitment of macrophages. The inflammatory response created by macrophage and neutrophil recruitment promotes angiogenesis, as well as melanoma cell invasion, survival, and metastasis. UVB also independently regulates melanin production and MC1R signaling. Induction of pigmentation genes and subsequent increase in melanin production following UVB increases cell survival and NER, but decreases proliferation and ultimately, melanomagenesis. Signaling through MC1R is induced by UVB and activates DNA damage response. Signaling through $\alpha$ MSH and MC1R promotes phosphorylation of ATM and ATR, upregulates XPC, and promotes XPA recruitment to stimulate NER. $\alpha$ MSH also activates oxidative stress response genes to reduce oxidative stress in melanocytes/melanoma. UVB-induced expression of IL23 also activates XPC and XPA to induce NER. IL-23 signaling, melanin production, and MC1R signaling can all inhibit melanomagenesis induced by UVB. Abbreviation: Activating Transcription Factor 2 (ATF2); Chemokine (C-C motif) Receptor 2 (CCR2); Chemokine (C-C motif) Ligand 2 (CCL2); Matrix Metalloproteinase-9 (MMP-9); type II Interferon (IFN- $\gamma$ ); Interleukin-23 (IL-23); Nucleotide Excision Repair (NER); Melanocortin 1 Receptor (MC1R); Ataxia-Telangiectasia Mutated gene (ATM); $\alpha$-Melanocyte-Stimulating Hormone $(\alpha \mathrm{MSH})$; Ataxia Telangiectasia and Rad3-related (ATR); Xeroderma Pigmentosum Group C (XPC); Xeroderma Pigmentosum group A (XPA).

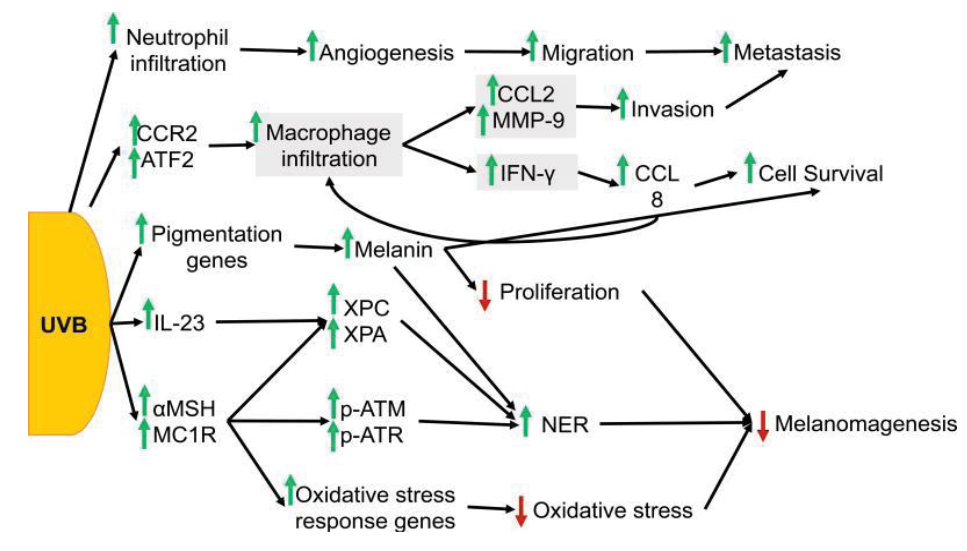

changes including wrinkle formation or by histological changes in connective tissues. In order to generate more wrinkles, vasculature structures are needed to develop. Numerous reports suggested that angiogenesis plays a significant role in inducing wrinkle formation in photo-damaged skin [39]. Among harmful environmental factors that contribute to extrinsic aging, long-term effects of repeated exposure to ultraviolet light are the most significant and are referred to as photoaging. Premature skin aging and development of malignant cutaneous tumors, melanoma and nonmelanoma, are interrelated issues that are increasingly important problems in the field of dermatology. Skin aging is important aesthetically, whereas skin cancer is a direct threat to the health of the patient [40]. Photoaging is a multisystem degenerative process that involves the skin and skin support system. It is a cumulative process and depends primarily on the degree of sun exposure and skin pigment. The epidermis and dermis are both affected by UVB, but the dermis is also affected to a significant extent by UVA. It has long been thought that the majority of human photo-lesions due to UVB rays, now it is believed that UVA play a substantial role in photoaging. Photoaging affects the sun-exposed areas and is characterized clinically by fine and coarse wrinkling, roughness, dryness, laxity, teleangiectasia, loss of tensile strength and pigmentary changes [41]. These changes are more severe in individuals with fair skin and are further influenced by individual ethnicity and genetics. Photoaging may be prevented and treated with a variety of modalities, including topical retinoids, cosmeceuticals, chemical peels, injectable neuromodulators, soft tissue fillers, and light sources [42]. There is also an increase in development of benign and malignant neoplasms on photoaged skin. During the years the progress has been made in understanding the photoaging in human skin. UV irradiation invokes a complex sequence of specific molecular responses that damage skin connective tissue [43]. In severely damaged skin, there is loss of epidermal polarity (orderly maturation) and individual keratinocytes may show atypia, especially the lower epidermal layers. More profound changes occur in the dermis, where photodamage is characterized by degeneration of collagen and deposition of abnormal elastotic material, reflected by wrinkles, furrows, and yellow discoloration of the skin. The greater the photodamage, the more the accumulation of thickened, tangled and degraded elastic fibers [44]. The application of topical growth factors after microneedling can be useful to reduce visual signs of facial photoaging by improving skin texture and minimizing the appearance of fine lines and wrinkles. Amongst retinoids, tretinoin is the most potent and best-studied retinoid. However, its irritation potential has prompted dermatologists to switch over to less irritating but comparably effective retinoids like adapalene and to some extent retinol and retinaldehyde [45]. Bakuchiol (functional analogue of topical retinoids, as both compounds have been shown to induce similar gene expression in the skin) is a phytochemical that has demonstrated cutaneous 
Exhibit 2: Environmental Factors That Influence Ultraviolet Radiation [32-36].

- Ozone layer: The main absorber of UVR, is produced for the most part in the terrestrial stratosphere of the equatorial region of the planet. Ozone layer is the name given to the region with high concentration of this gas in the Earth's atmosphere, located at a height between 15 and $30 \mathrm{~km}$. This layer contains between 80 and $90 \%$ of the total ozone in the terrestrial atmosphere and is responsible for the intensive absorption of UVB radiation and part of the extinction of UVC radiation.

- Altitude: The higher the altitude of a location, the thinner is the atmosphere above it and, consequently, the larger the quantity of UVR reaching the surface. In situations of clear and cloudless skies, the UVR flux may increase between 5 and $10 \%$ for each $1000 \mathrm{~m}$ altitude. Nevertheless, this altitude-related increase in URV may vary to values close to $20 \%$ per kilometer, as it depends on a series of other factors, such as the quantity of ozone in the lower layers of the atmosphere, the type of surface that reflects UV radiation, the particulates present in the atmosphere and even the position of the sun.

- The time of day: In a clear sky situation, the "higher" the Sun is in the sky, the higher the levels of UV radiation are. This means that the farther the Sun is from the horizon, the shorter the optical pathway the radiation has to cross in the atmosphere.

- The season of the year: In the summer, the Sun reaches higher positions in relation to the horizon than in the winter and, consequently, the UVR flux is more intense. The differences between the seasons of the year become more relevant as the latitude becomes higher

- Clouds: Clouds can both attenuate and enhance UVB radiation, although attenuation is generally the case. Completely overcast clouds always attenuate UVB rays, even up to $99 \%$ of UVB radiation in extreme cases. Up to $50 \%$ enhancement of UVB radiation can occur from broken clouds [39] or at elevated sites above clouds.

- Suspended Particles: Polluted environments or those with suspended dust may show UVR attenuation in relation to clear sky situations. Some studies demonstrate that polluted locations, such as São Paulo or Mexico City, may present situations with around $20 \%$ of the incident UVR.

- Surface reflection (albedo): The term 'albedo' is used to express the relationship between the radiation reflected by a surface and the radiation such surface receives from the Sun. Very light colored surfaces, such as freshly fallen snow, may reflect up to $90 \%$ of the incident radiation; therefore, wearing adequate protection for the eyes and skin is required in environments like mountains and ski tracks.

- Outdoor Vs Indoor Working: Outdoor workers can get three to nine times as much solar UVR exposure as indoor workers. Paradoxically, outdoor workers have a lower incidence of cutaneous malignant melanoma compared to indoor workers. It is supposed that indoor solar UVA exposure, which causes mutations, depletes vitamin D3 in the skin. Behavior includes the time spent outdoors and the use of photoprotective agents. In adult life, a British indoor worker in the UK might typically receive $30 \%$ of his or her annual UV exposure from sun-seeking holidays, $40 \%$ from summer weekends, $20 \%$ from casual weekday exposure between April and September and just $10 \%$ from sun exposure during the 6 months period October to March.

antiageing effects when applied topically. Bakuchiol is promising as a more tolerable alternative to retinol [46] (Figure 4) (Exhibit 3, 4).

\section{Sunburn Home Remedies and Treatment}

Certain medical treatments have been tried and studied to treat sunburn. However, in general, most remedies have not shown any clinically proven benefit as far as speeding the recovery or reversing the damage. Therefore, most of the treatments available are only used to treat symptoms.

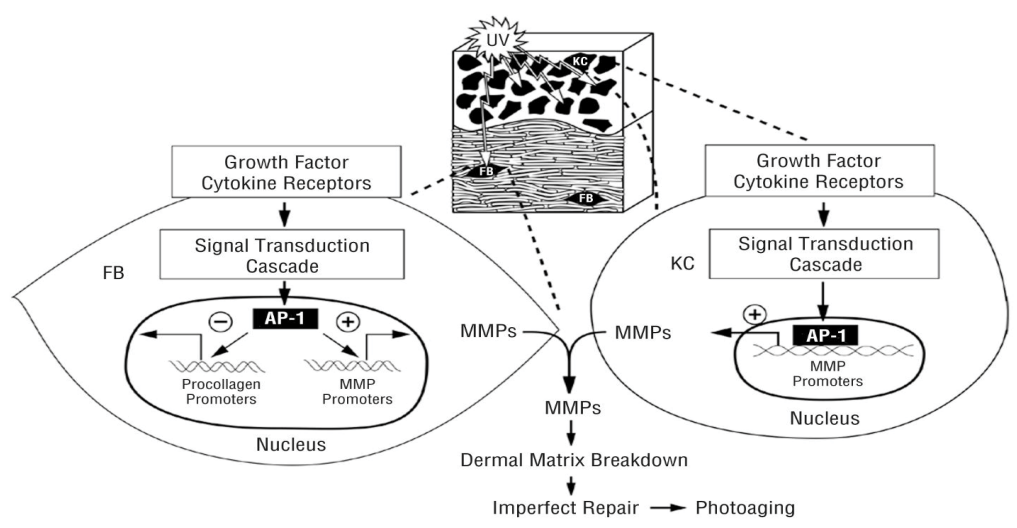

Figure 4: Mechanisms of Photoaging and Chronological Skin Aging [143], [147-150]. Photodamaged skin displays variable epidermal thickness, dermal elastosis, decreased/fragmented collagen, increased matrix-degrading metalloproteinases, inflammatory infiltrates and vessel ectasia. The main effects of acute and chronic exposure to UV radiation are DNA damage, inflammation and immunosuppression. These effects are direct as well as indirect due to ROS production. The ROS are particularly harmful in that they destabilize other molecules and promote chain reactions that damage biomolecules rapidly, such as telomere shortening and deterioration, mitochondrial damage, membrane degradation and oxidation of structural and enzymatic proteins. Collagen and elastin are the structural proteins of the ECM. The deterioration/remodeling of the collagen and elastin fibers facilitates angiogenesis and metastasis, and the damaged collagen and elastin proteins serve as additional sensitizers of photooxidative stress. Accumulation of collagen fragments, which occurs with chronic UV exposure and the passage of time, impairs the mechanical and functional properties of the dermal extracellular matrix. Elastic fibres, such as oxytalan fibres in papillary dermis, are associated with not only skin resilience, but also skin surface texture, and elastic fibre formation by fibroblasts is facilitated by increased expression of fibulin-5. Thus, induction of fibulin-5 expression is a damage-repair mechanism, and fibulin-5 is an early marker of photoaged skin. 
Exhibit 3: Comparison between photo aging and intrinsic aging [130]

\begin{tabular}{|c|c|c|}
\hline Particular & Photoaging & Intrinsic aging \\
\hline \multirow{6}{*}{$\begin{array}{l}\text { Epidermal } \\
\text { changes }\end{array}$} & $\begin{array}{l}\text { Thickness increases, acanthropic in early phase and atrophy in later } \\
\text { stages }\end{array}$ & Thin epidermis \\
\hline & Proliferative rate is higher than normal & Proliferative rate is lower than normal \\
\hline & $\begin{array}{l}\text { Non-uniform and random distribution of keratinocytes, polarity of cells is } \\
\text { lost, frequent enlargement }\end{array}$ & $\begin{array}{l}\text { Uniform and defined distribution of keratinocytes, } \\
\text { polarity is maintained, usually atrophied }\end{array}$ \\
\hline & Diversifi ed melanosomes & Uniformly distributed melanosomes \\
\hline & Increased number of stratum corneum (SC) cell layer & Normal cell layer \\
\hline & Vitamin A content is destroyed by sun exposure & Plasma content of retinol increases \\
\hline \multirow{8}{*}{$\begin{array}{l}\text { Dermal } \\
\text { changes }\end{array}$} & Marked elastogenesis followed by massive degeneration & Elastogenesis followed by elastolysis \\
\hline & Massive increase in elastic fibers & Gradual decline in production of dermal matrix \\
\hline & Increased lysozyme deposition on elastic fibers & Modest lysozyme deposition on elastic fibers \\
\hline & Decrease in amounts of mature collagen & Mature collagen more stable in degradation \\
\hline & Increased mast cells & Decreased mast cells \\
\hline & Vessels become dilated & Micro vessels decrease \\
\hline & Pronounced inflammation & No inflammatory response \\
\hline & Marked increase in glycosaminoglycans & Slight decrease in glycosaminoglycans \\
\hline \multirow{3}{*}{$\begin{array}{l}\text { Common } \\
\text { signs and } \\
\text { symptoms }\end{array}$} & $\begin{array}{l}\text { Mild (age } 28-35 \text { years): Few wrinkles, no keratoses } \\
\text { Moderate (age } 35-50 \text { years): Early wrinkling, sallow complexion with early } \\
\text { actinic keratoses }\end{array}$ & $\begin{array}{l}\text { Fine wrinkles, thin and transparent skin } \\
\text { Loss of underlying fat leading to hollowed cheeks and } \\
\text { eye sockets with noticeable loss of firmness on the } \\
\text { hands and neck }\end{array}$ \\
\hline & $\begin{array}{l}\text { Advanced (age } 50-60 \text { years): Persistent wrinkling, discoloration of the skin } \\
\text { with telangiectases and actinic keratoses }\end{array}$ & $\begin{array}{l}\text { Bones shrink away from the skin as a result of } \\
\text { bone loss, which causes sagging of skin, dry skin with } \\
\text { pruritus }\end{array}$ \\
\hline & $\begin{array}{l}\text { Severe (age } 65-70 \text { years): Severe wrinkling, photo aging, gravitational } \\
\text { and dynamic forces affecting the skin, actinic keratoses with or without } \\
\text { skin cancer }\end{array}$ & $\begin{array}{l}\text { Inability to sweat sufficiently to cool the skin, faster } \\
\text { graying of hair }\end{array}$ \\
\hline
\end{tabular}

Exhibit 4: Exogenous antioxidants with photoprotective or damage protective effects [154].

\begin{tabular}{|c|c|}
\hline Antioxidants & Outcome of the study \\
\hline \multirow{4}{*}{ Ascorbic acid } & Topical vitamin C $5 \%$ cream applied for six months led to clinical improvement in the appearance of photoaged skin \\
\hline & Topical vitamin C stimulates the collagen-producing activity of the dermis \\
\hline & $\begin{array}{l}\text { Magnesium ascorbyl phosphate administration immediately after exposure in hairless mice significantly delayed skin } \\
\text { tumor formation and hyperplasia induced by chronic exposure to UV radiation }\end{array}$ \\
\hline & Ascorbic acid was a photoprotectant when applied to mice and pig skin before exposure to ultraviolet (UV) radiation \\
\hline \multirow{3}{*}{ Vitamin $\mathrm{E}$} & UV-induced vitamin E depletion \\
\hline & $\begin{array}{l}\text { The interaction of vitamin } E \text { with the eicosanoid system may result in an anti-inflammatory effect and thereby } \\
\text { complement the photoprotective effects of other antioxidants in the skin }\end{array}$ \\
\hline & Vitamin $\mathrm{E}$ has skin barrier-stabilizing properties \\
\hline \multirow{2}{*}{ Lycopene } & UV light decreased skin lycopene concentrations more so than skin $\beta$-carotene concentrations \\
\hline & Lycopene protects against UV-induced erythema in humans \\
\hline \multirow{6}{*}{$\begin{array}{l}\text { Carotenoids (carotene, } \\
\beta \text {-carotene, and } \\
\text { carotenoid mix) }\end{array}$} & $\begin{array}{l}\text { Carotenoids are efficient in photoprotection, scavenging singlet oxygen, and peroxyl radicals. Supplements or a } \\
\text { carotenoid-rich diet decreased sensitivity against UV-induced erythema }\end{array}$ \\
\hline & $\begin{array}{l}\text { Supplementation with carotenoids contributes to basal protection of the skin but is not sufficient to obtain complete } \\
\text { protection against severe UV irradiation }\end{array}$ \\
\hline & $\begin{array}{l}\text { Dietary beta-carotene has effect on wrinkles and elasticity, procollagen gene expression, and ultraviolet (UV)-induced } \\
\text { DNA damage in human skin }\end{array}$ \\
\hline & Erythema-protective effect of a carotenoid mix inhibited serum lipid peroxidation \\
\hline & Presupplementation with $\beta$-carotene before and during sunlight exposure provides protection against sunburn \\
\hline & Inhibition of UV-induced epidermal damage and tumor formation in mouse models \\
\hline \multirow{3}{*}{ Tretinoin } & Topical tretinoin ameliorates the clinical signs of photoaging \\
\hline & The treatment of photodamaged skin with tretinoin increased collagen I formation. \\
\hline & Topical tretinoin is safe and effective in the treatment of photodamage \\
\hline
\end{tabular}




\begin{tabular}{|c|c|}
\hline Antioxidants & Outcome of the study \\
\hline & Improvement in photodamaged skin \\
\hline & Topical tretinoin reduced the effects of photoaging \\
\hline & Topical tretinoin in combination with sun protection as a useful approach to the treatment of sun-damaged skin \\
\hline \multirow{3}{*}{$\begin{array}{l}\text { Coenzyme Q10 } \\
(\text { CoQ10) }\end{array}$} & Topical application of CoQ10 has the beneficial effect of preventing photoaging \\
\hline & $\begin{array}{l}\text { Coenzyme Q10 protects against oxidative stress-induced cell death and enhances the synthesis of basement } \\
\text { membrane components in dermal and epidermal cells }\end{array}$ \\
\hline & CoQ10 was shown to reduce UVA-induced MMPs in cultured human dermal fibroblasts \\
\hline Glutathione & Glutathione is a photoprotective agent in skin cells \\
\hline \multirow{2}{*}{ Zinc } & Zn-treated fibroblasts were more resistant to UVR than cells grown in normal medium \\
\hline & Zn can positively influence the effects of oxidative stress on cultured human retinal pigment epithelial (RPE) cells \\
\hline Resveratrol & $\begin{array}{l}\text { Application of resveratrol to the skin of hairless mice effectively prevented the UVB-induced increase in skin thickness } \\
\text { and the development of the skin edema }\end{array}$ \\
\hline \multirow[b]{2}{*}{ Green tea } & Green tea polyphenols were shown to reduce UV light-induced oxidative stress and immunosuppression \\
\hline & $\begin{array}{l}\text { Topical treatment or oral consumption of green tea polyphenols (GTP) inhibits chemical carcinogen- or UV radiation- } \\
\text { induced skin carcinogenesis in different laboratory animal models }\end{array}$ \\
\hline Green tea or caffeine & $\begin{array}{l}\text { Oral administration of green tea or caffeine in amounts equivalent to three or five cups of coffee per day to UVB- } \\
\text { exposed mice increased levels of p53, slowed cell cycling, and increased apoptotic sun burn cells in the epidermis }\end{array}$ \\
\hline \multirow{2}{*}{ Sylimarin } & Silymarin strongly prevents both photocarcinogenesis and skin tumor promotion in mice \\
\hline & Skin cancer chemopreventive effects \\
\hline Genistein & Antioxidant and anticarcinogenic effects on skin \\
\hline \multirow{2}{*}{ Cocoa } & $\begin{array}{l}\text { Dietary flavanols from cocoa contribute to endogenous photoprotection, improve dermal blood circulation, and affect } \\
\text { cosmetically relevant skin surface and hydration variables }\end{array}$ \\
\hline & Photoprotection against UV-induced erythema \\
\hline
\end{tabular}

- Nonsteroidal anti-inflammatory drugs (NSAIDs): Systemic and topical nonsteroidal antiinflammatory drugs, when used at dosages to achieve optimal serum levels for anti-inflammatory effect, only result in an early and mild reduction of ultraviolet B-induced erythema [47]. In oral (ibuprofen, Motrin, Naprosyn, Advil etc.) or topical diclofenac $0.1 \%$ gel (Solaraze) forms have shown to reduce redness if applied before or immediately after UVB exposure. This benefit may be diminished after 24 hours. These medications may also help relieve the symptoms of sunburn such as pain and discomfort [12].

- Topical steroid creams: have not shown any significant improvement in sunburn symptoms. Oral steroids such as prednisone have not proven to be beneficial and have been associated with some significant side effects. Treatment with topical moderate-potency or high-potency corticosteroids does not provide a clinically useful decrease in the acute sunburn reaction when applied 6 or 23 hours after UV exposure [48].

- Applying Aloe Vera gel: Topical application of Aloe Vera is not an effective prevention for radiationinduced injuries and has no sunburn or suntan protection [49]. The Aloe Vera cream was continuing applied at the test sites twice daily for the next three weeks. The results showed no sunburn or suntan protection and no efficacy in sunburn treatment when compared to placebo. The Aloe Vera cream has no bleaching effect too. However, this may be beneficial in treating the symptoms [50].

- Topical anesthetics: Advertised remedies such as topical anesthetics (benzocaine) may help with symptoms of sunburn, however, very little clinical data is available to substantiate their effectiveness. LMX is a topical liposomal formulation containing $4 \%$ or $5 \%$ lidocaine. LMX $4 \%$ is available OTC and is FDA-approved for temporary relief of pain and itching associated with minor cuts, minor burns, sunburn, and insect bites [51].

- Vitamin D Preparations: Vitamin D enables anti-inflammation to promote tissue repair in 
response to injury. Mechanistically, vitamin D signaling activated M2-autophagy regulators Kruppel like factor 4 (KLF4), peroxisome proliferator activated receptor gamma (PPARG), and arginase 1. Analysis of UV-exposed human skin biopsies detected a similar increase in macrophage autophagy following vitamin D intervention, identifying an essential role for autophagy in vitamin D-mediated protection of skin from UV damage [52].Sunscreens: Sunscreens represent a practical approach to photoprotection for skin. The importance of beginning sun protection at a young age cannot be overstated. In humans, the regular use of sunscreens has been shown to reduce AKs, solar elastosis, UV-induced immunosupression, and photosensitivities. Sunscreens also prevent the formation of SCCs in animals. A thorough understanding of the mechanism of action of sunscreens, different sunscreen vehicle choices, and adverse effects can help educate patients on their choice of sunscreens [1] (Figure 5).

\section{Medication responsible for increase skin sensitivity to sunlight}

A large number of medications are known to increase skin sensitivity to sunlight and are called photosensitive drugs or medications. Photo-sensitizing chemicals usually have a low molecular weight (200 to 500 Daltons) and are planar, tricyclic, or polycyclic configurations, often with heteroatoms in their structures enabling resonance stabilization. All absorb UV and/or visible radiation, a characteristic that is essential for the chemical to be regarded as a photosensitizer. Some of the common ones include:

NSAIDs (nonsteroidal anti-inflammatory drugs)

Antibiotics: Tetracyclines (tetracycline, doxycycline [Vibramycin]), Quinolone (ciprofloxacin [Cipro], levofloxacin [Levaquin]), Sulfonamides (sulfamethoxazole and trimethoprim; cotrimoxazole [Bactrim, Septra], sulfamethoxazole [Gantanol]).

Diuretics (water pills): thiazides (hydrochlorothiazide [Hydrodiuril], furosemide [Lasix])

Cardiac medications: amiodarone (Cordarone), quinidine

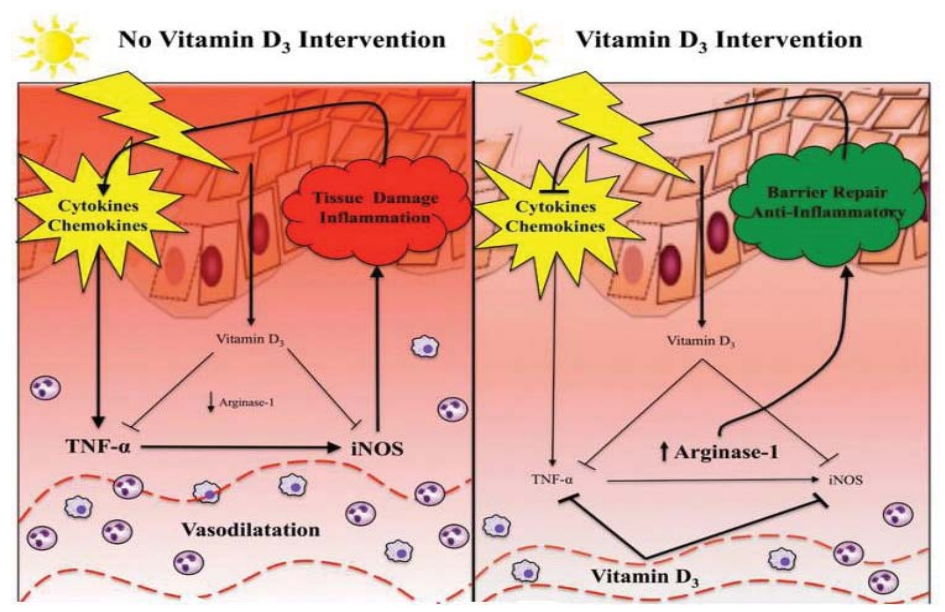

Figure 5: The Effect of Oral Vitamin D3 Intervention on Skin Inflammation [26]. As depicted in panel A, levels of vitamin D3 are at baseline levels in the absence of high dose oral vitamin D3 intervention. In this context, exposure to erythemogenic doses of UVR results in sunburn and the release of pro-inflammatory cytokines and chemokines in the skin, including TNF- $\alpha^{* *}$ and iNOS*, which further propagate tissue inflammation. Increased skin redness and thickness are mediated by vasodilation, an influx of inflammatory cells, and vascular congestion within the skin. The gene expression profile of skin at this time is characterized by increased expression of various pro-inflammatory genes. As depicted in panel B, levels of vitamin D3 rapidly rise within the serum after high dose oral vitamin D3 intervention. Arginase- 1 is up regulated within the skin, and production of the proinflammatory mediator's TNF- $\alpha$ and iNOS are attenuated after sunburn. Reduced skin erythema and thickness are observed clinically. The gene expression profile of skin at this time is characterized by increased expression of skin barrier genes, which help to repair the epidermal barrier and attenuate the inflammatory insult. *iNOS is the synthase isoform most commonly associated with malignant disease.** TNF- $\alpha$ is a primary cytokine that can be induced in keratinocytes and in dermal fibroblasts by UVB, synthesized in adipose tissue by adipocytes and other cells in the tissue matrix. TNF- $\alpha$ is mainly secreted by activated macrophages immediately postburn. The host immune response is activated by TNF- $\alpha$, as is the subsequent release of cytokines following trauma and infection. 
Diabetes drugs: sulfonylureas such as chlorpropamide (Diabinese), glyburide (Micronase, DiaBeta, Glynase)

Psychiatric drugs: chlorpromazine (Thorazine), tricyclic antidepressants such as desipramine (Norpramin) and imipramine (Tofranil)

Acne medications: isotretinoin (Accutane) [53-58], (Figure 6) (Exhibit 5, 6).

\section{Tanning/Pigmentation with or without Sun Exposure}

Some Africans and Asians avoid sun and use bleaching products to lighten skin, while many Caucasians

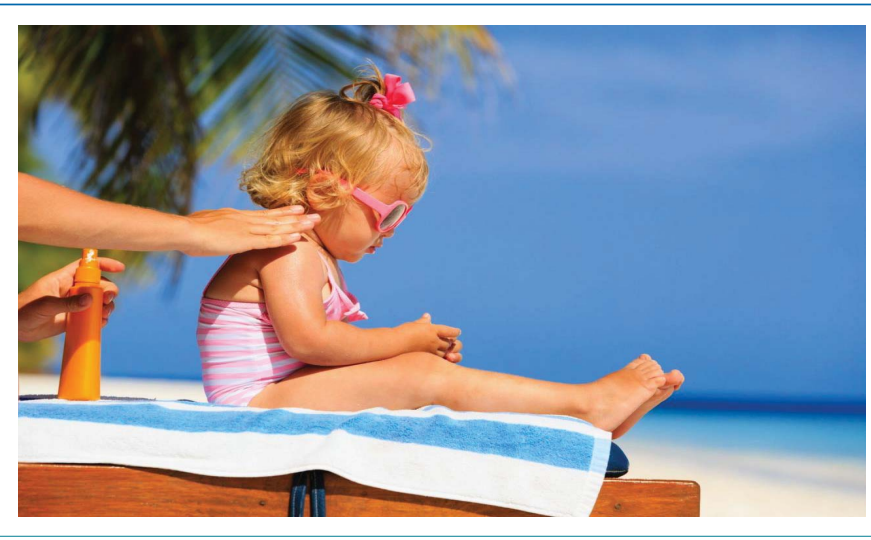

Figure 6: Use of Sun Protective [178]. Public guidelines for sun protection have been updated as stakeholders warn that Australians are using sunscreen as a "suit of armour". Heather Walker, chair of Cancer Council Australia's National Skin Cancer Committee, said that recent research shows $85 \%$ of people do not apply sunscreen correctly. The Australasian College of Dermatologists and Cancer Council updated the guidelines following concerns that many Australians only use sunscreen to protect their skin. By not using clothing, a broad-brimmed hat, shade, sunglasses and sunscreen correctly when the ultraviolet index reaches three or above, they are putting themselves at risk, the organizations say. seek the sun for tanning to achieve a bronze skin to "look good." UV radiation from the sun or from artificial sources increases skin pigmentation. Sunlight and indoor UV induced tanning is a common behavior, especially among adolescents, young adults, and individuals with lighter skin. Several health benefit claims such as improved appearance, enhanced mood, and increased vitamin D levels have been attributed to tanning. The Indoor Tanning Association claims that a base tan can act as "the body's natural protection against sunburn. Sunless tanning products may serve as a sensible, safer alternative for those who desire tanned skin [59]. There are three phases of tanning: immediate pigment darkening (IPD), persistent pigment darkening (PPD) and delayed tanning (DT). IPD occurs during

\begin{tabular}{|l|l|}
\hline \multicolumn{2}{|l|}{ Exhibit 5: Cosmetic ingredients and cancer risk [34]. } \\
\hline Cosmetic substance & Risk \\
\hline $\begin{array}{l}\text { DEA (diethanolamine) } \\
\text { TEA (triethanolamine) }\end{array}$ & Can result in formation of carcinogenic nitrosamines \\
\hline Bronopol (2-bromo-2-nitropropane-1,3-diol) & May break down into formaldehyde and also cause the formation of nitrosamines \\
\hline 1,2-Dioxane in surfactants/detergents & Contaminated with carcinogenic 1,4-dioxane \\
\hline Artificial colors (as Blue 1 and Green 3) & Carcinogenic \\
\hline Hair dyes & Dark colors ingredients are carcinogenic \\
\hline Cosmetic lanolin & $\begin{array}{l}\text { Can be contaminated with carcinogenic pesticides such as DDT, dieldrin, and lindane, in addition } \\
\text { to other neurotoxic pesticides }\end{array}$ \\
\hline Talc & Carcinogenic \\
\hline Silica & May be contaminated with carcinogenic crystalline quartz \\
\hline $\begin{array}{l}\text { Disrupting effects toward thyroid hormone } \\
\text { receptor }\end{array}$ & Decrease of T4 level; Inhibition of the conversion of T4 to triiodothyronine in rats \\
\hline $\begin{array}{l}\text { Disrupting effects toward other nuclear } \\
\text { receptors }\end{array}$ & $\begin{array}{l}\text { Antagonists of PR and AR; Inhibition of 4,5-dihydrotestosterone activity; Reduce of the prostate } \\
\text { and testicular weight in rats }\end{array}$ \\
\hline
\end{tabular}

the first minutes of exposure to UVA, and then fades within few hours. PPD appears within hours of higher doses of UVA exposure and persist up to several days or weeks. DT develops over 3-7 days after UVB exposure, and then remains for weeks. The mechanisms of UVA- and UVB-induced pigmentation are different. UVA induces IPD and PPD through oxidation of pre-existing melanin or melanogenic precursors. IPD is oxygen dependent, and reactive oxygen radicals are considered to be responsible for this process. PPD is also due to the upward movement of melanosomes toward the surface of the skin. Persons with 


\begin{tabular}{|c|c|c|}
\hline UV Filters & Endocrine Disrupting Effe & \\
\hline \multirow{3}{*}{ Benzophenones } & $\begin{array}{l}\text { Estrogenic disrupting } \\
\text { effects }\end{array}$ & $\begin{array}{l}\text { Activation of ERa, ERß; Inhibition of the activity of } 17 \beta \text {-Estradiol; Induction of } \\
\text { proliferation of MCF-7 cell; Induction of VTG in fathead minnows; Reduce of the uterine } \\
\text { weight in immature Long-Evans rats }\end{array}$ \\
\hline & $\begin{array}{l}\text { Androgenic disrupting } \\
\text { effects }\end{array}$ & $\begin{array}{l}\text { Antagonists of human AR transactivation; Repression of 4,5-dihydrotestosterone- } \\
\text { induced transactivational activity; Inhibition of testosterone formation in mice and rats }\end{array}$ \\
\hline & $\begin{array}{l}\text { Disrupting effects toward } \\
\text { other nuclear receptors }\end{array}$ & $\begin{array}{l}\text { Inhibition of human recombinant TPO; Interference with THR; Inhibition of TPO activity } \\
\text { in rats; Antagonists of PR }\end{array}$ \\
\hline \multirow{3}{*}{$\begin{array}{l}\text { Camphor } \\
\text { derivatives }\end{array}$} & $\begin{array}{l}\text { Disrupting effects toward } \\
\text { estrogen receptor }\end{array}$ & $\begin{array}{l}\text { Activation of ERa, ERB; Inhibition of the activity of } 17 \beta \text {-Estradiol; Induction of } \\
\text { proliferation of MCF-7 cell; Induction of pS } 2 \text { protein in MCF-7 cells; Reduce of the } \\
\text { uterine weight in rats; Induction of VTG in fish }\end{array}$ \\
\hline & $\begin{array}{l}\text { Disrupting effects toward } \\
\text { androgen receptor }\end{array}$ & $\begin{array}{l}\text { Repression of 4,5-dihydrotestosterone-induced transactivational activity; Inhibition of } \\
\text { testosterone formation in HEK-293 cells; Antagonists of Human AR }\end{array}$ \\
\hline & $\begin{array}{l}\text { Disrupting effects toward } \\
\text { progesterone receptor }\end{array}$ & $\begin{array}{l}\text { Antagonists of PR; Increase of PR mRNA levels in rats; Inhibition of the expression of } \\
\text { PR protein in rats; Disturbance of the expression of membrane-associate PR in insects }\end{array}$ \\
\hline \multirow{3}{*}{$\begin{array}{l}\text { Cinnamate } \\
\text { derivatives }\end{array}$} & $\begin{array}{l}\text { Disrupting effects toward } \\
\text { estrogen receptor }\end{array}$ & $\begin{array}{l}\text { Activation of ERa; Inhibition of the activity of } 17 \beta \text {-Estradiol; Induction of proliferation of } \\
\text { MCF-7 cell; Reduce of the uterine weight in rats; Induction of VTG in fish }\end{array}$ \\
\hline & $\begin{array}{l}\text { Disrupting effects toward } \\
\text { thyroid hormone receptor }\end{array}$ & Decrease of T4 level; Inhibition of the conversion of T4 to triiodothyronine in rats \\
\hline & $\begin{array}{l}\text { Disrupting effects toward } \\
\text { other nuclear receptors }\end{array}$ & $\begin{array}{l}\text { Antagonists of PR and AR; Inhibition of 4,5-dihydrotestosterone activity; Reduce of the } \\
\text { prostate and testicular weight in rats }\end{array}$ \\
\hline
\end{tabular}

lightest skin (skin type I) do almost not tan, while IPD and PPD are strongest in moderately and darkly pigmented skin. DT results from synthesis of melanin in the melanocytes, followed by melanin distribution to neighboring keratinocytes [60]. UVA (320-400 nm) causes immediate pigment darkening (IPD) as well as persistent pigment darkening (PPD) of skin within hours via photooxidation and/or polymerization of existing melanin or melanogenic precursors due to the generation of reactive oxygen species In contrast, UVB (280-320 nm) induces a slower but more stable type of pigmentation termed delayed tanning (DT) which requires the increased synthesis of melanin following the stimulation of tyrosinase activity and the entire melanogenic cascade [61]. UVB-induced DT is photoprotective (it is estimated to have a SPF of 3)- while DT induced by UVA is not considered to be photoprotective. DT is maximal from 10 days to 3-4 weeks, depending on the UV dose and the individual's skin color. It may take several weeks or months for the skin to return to its base constitutive color. UVA-induced DT is 2-3 orders of magnitude less efficient per unit dose than UVB and has an earlier onset, often directly after IPD [62]. The IPD method can also be used as an appropriate endpoint in the determination of UVA protection. It is time saving, and thus considerably lowers the risk of UV exposure, particularly when testing sunscreen products with higher UVAPF [63]. IPD typically appears gray to black while PPD is brown. Both IPD and PPD do not require any new pigment synthesis and are thought to result from oxidation and/or polymerization of pre-existing melanin or melanogenic precursors and metabolites. Melanosomes have also been shown to redistribute within both keratinocytes and melanocytes during the IPD/PPD response. PPD is not protective against neither UVB-induced erythema nor UVB-induced DNA lesions [64]. Exposure to ultraviolet radiation from indoor tanning device use is associated with an increased risk of skin cancer, including risk of malignant melanoma, and is an urgent public health problem. By reducing indoor tanning, future cases of skin cancer could be prevented, along with the associated morbidity, mortality, and healthcare costs [65] (Figure 7) (Exhibit 7, 8).

\section{The Sun Care Industry}

The U.S. sun care market size was estimated at USD 1.95 billion in 2016. The growing consumer awareness regarding the ill-effects of over exposure to ultraviolet (UV) rays on the undefended skin is expected to propel growth. Furthermore, rising utilization of organic sun care products owing to absence of synthetic chemicals in the formulation is expected to drive growth over the forecast period. The sunscreen 


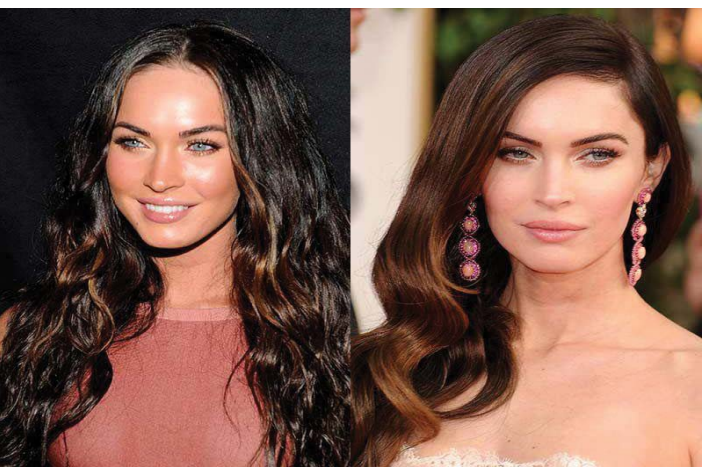

Figure 7: Give me a tan! - Megan Fox [176,177]. Megan Fox comes up the most when searching online for pale vs. tan photos. She demanded a sun bed be delivered to the set of Transformers: Revenge of the Fallen, because she was feeling self-conscious about her pale skin, according to Fox News. But they didn't have one available so offered to send an expert to give Megan a customized spray tan. However, Megan turned down the offer, saying she wanted a sun bed instead.

\section{Exhibit 7: Common Tanning Methods [171-174]}

1. UV Tanning: Tanning salons offer an indoor method of UVR with tanning beds and booths. These salons expose people to man-made UV light. Tanning beds were introduced in North America in 1978 and gained considerable popularity in the 1980s. Indoor tanning salons are a common choice among those who tan as they do not require people to spend hours outside in the sunlight. At any given tanning salon, there are typically three to five different types of beds. They are classified as level 1 through 6 . In general, increasing levels correspond to increasing concentrations of UVA relative to UVB. Increasing the bed level also increases the pressure and number of lamps, resulting in a deeper tan that appears faster and fades slower than lower level beds. In tanning salons, the user has the option to stand (e.g., in a booth) or lie supine (e.g., in a bed). The time spent in a bed is limited by the strength of lamps used and ranges from 8 to 20 minutes. One of the most important differences between beds is the percent of UVA versus UVB light.

2. Tanners for Topical Use: Topical sunless tanners are products that are applied to the skin to give the appearance of a tan. These products come in many forms including lotions, gels, mousses, sprays, wipes, creams, and powders. Temporary bronzers are one type of topical self-tanner. Bronzers come in creams, lotions, and powders. When a bronzer is applied to the skin, it coats the outer layers of the epidermis. Bronzers are considered temporary because they only last until they are washed off by normal soap and water use. The use of a bronzer is similar to putting on make-up every day. Commonly used ingredients for temporary bronzers include caramel, walnut oil extract, and jojoba extract. DHA formulations have become popular among the public due to their relative ease of application and longer lasting tan when compared to temporary color bronzers, which wash off readily with soap and water. The temporary color bronzers also have a higher tendency to cause blotchiness, an uneven tan, and a less natural looking color. DHA is not approved for use on non-skin areas, such as the eyes, lips, and mucous membranes. As a result, DHA has not been approved in the use of spray tanning booths due to the potential exposure to non-FDA approved sites, even when taking precautions, such as wearing nose plugs, goggles, or applying petroleum jelly to the lips.

3. Tanning Pills: The FDA has banned canthaxanthin-containing tanning pills due to their significant adverse effects when ingested in large quantities. Some of the side effects include gastrointestinal disturbance, urticaria, hepatitis, retinopathy, and potentially fatal aplastic anemia. Tanning pills are non-prescription formulations that are readily available to customers for purchase over the Internet. The most common active ingredient is canthaxanthin. Another common ingredient in tanning pills is beta-carotene, a different carotenoid. Beta-carotene is obtained through the dietary consumption of fruits and vegetables, and it contributes to the yellow pigment found in human skin. Its deposition in the skin is thought to contribute to photoprotection, guarding against the deleterious effects of both natural and artificial UV light exposure, and raising the minimum amount of UVR exposure required to cause a sunburn.

4. Alpha-Melanocyte Stimulating Hormone Analogues: Afamelanotide is a subcutaneous implant administered once a month. It has been approved for erythropoietic protoporphyria in Europe. Other analogues of alpha-MSH, Melanotan I and II, are available and unregulated to enhance skin pigmentation for cosmetic tanning. They are not equivalent to afamelanotide. They have been reported to cause side effects, such as satiety, hypertension, and penile erections. Other risks include the potential to transmit blood-borne infections, rhabdomyolysis, encephalopathy, and renal dysfunction. These side effects have not been reported with the controlled-release subcutaneous afamelanotide implant that is undergoing clinical trials.

Exhibit 8: Future research opportunities to inform efforts to reduce indoor tanning in the US [175].

\section{Individual-level strategies}

- Continue to develop and evaluate tailored and targeted messaging strategies.

- Evaluate the long-term impact that messages have on indoor tanning behaviors.

- Test the efficacy of behavioral counseling among groups other than female undergraduate tanners.

The roles of parents, clinicians, and schools

- Assess parents' perceptions of the risks associated with indoor tanning.

- Assess parents' awareness of their children's use of indoor tanning devices.

- Examine the prevalence of the practice of parents doing indoor tanning with their children.

- Evaluate strategies for engaging parents in prevention efforts targeting children.

- Identify ways to disseminate information about and tools for behavioral counseling to clinicians.

- Monitor clinicians' behavioral counseling practices.

- Develop and evaluate educational, systems, and environmental interventions in school settings. 
Mass media campaigns

- Develop and evaluate the efficacy of mass media campaigns.

- Engage celebrities and other public figures in mass media campaign efforts.

\section{Legislation}

- Track the development and implementation of new indoor tanning legislation.

- Compare the effects of various types of indoor tanning legislation on behaviors.

- Develop informational resources for decision makers.

- Monitor public support for indoor tanning legislation.

\section{Assessment, monitoring, and evaluation}

- Continue surveillance efforts at the national level to track indoor tanning device use.

- Increase surveillance efforts at the state and local levels to track indoor tanning device use.

- Collect data on the prevalence and use of unsupervised indoor tanning devices.

- Monitor indoor tanning attitudes and beliefs among the U.S. population and among indoor tanners.

- Monitor trends in outdoor tanning (i.e., sunbathing).

- Conduct economic analyses to quantify the impact on morbidity, mortality, productivity, and health care costs.

- Monitor trends within the indoor tanning industry over time (e.g., industry size and pricing).

- Continue surveillance of melanoma incidence and mortality rates.

- Collect data on basal and squamous cell carcinomas using electronic medical records.

- Conduct modeling studies to estimate trends in the incidence of basal and squamous cell carcinomas.

manufacturers are actively using these formulations as it increases the endurance of skin cells against UV rays and enhances the self-defense mechanism. Enhanced standard of living coupled with increasing disposable income of the middle-class working population in economies of North America, including the U.S., is expected to propel sun care market growth over the forecast period. The industry players including L'Oréal are using nanotechnology by manipulating the materials at an atomic or molecular in order to enhance the efficiency of the product. Over the past five years, the Sunscreen Manufacturing industry has grown by $1.6 \%$ to reach revenue of $\$ 407 \mathrm{~m}$ in 2018 . In the same timeframe, the number of businesses has grown by $3.9 \%$ and the number of employees has grown by $1.5 \%[66,67]$. 


\section{Classification of Sunscreens}

Sunscreens are classically divided into physical or chemical sunscreens. Chemical sunscreen absorbs into the skin and then absorbs UV rays, converts the rays into heat, and releases them from the body. Physical blockers are inorganic and reflect, scatter, and/or absorb UVR. Physical UV absorbers like titanium dioxide and zinc oxide have been considered as highly protective agents against UVR. $\mathrm{ZnO}$ and TiO2 combinations are particularly valuable because of their ability to filter both UVA and UVB radiations, providing broader UVR protection than that observed with individual component [68]. They are used in sunscreens as nanoparticles, which denotes a size $<100 \mathrm{~nm}$. The smaller size of these mineral particles increases their cosmetic acceptability by users as they are much less visible after application. ZnO has a broad UVA-UVB absorption curve, while TiO2 provides better UVB protection. Overall, the human health risks with inorganic filters are extremely low given a lack of percutaneous absorption; however, there is potential risk when exposed via inhalation, prompting recommendations against spray sunscreen products with nanoparticles [69]. UV-A rays heavily contribute to both premature skin aging and skin cancer, while UV-B rays cause sunburn. Hence, the use of sunscreen is strongly encouraged by many healthcare practitioners in order to minimize or possibly eradicate the harmful effects of UV rays on our skin, keeping in mind, that about $90 \%$ of all skin cancers are associated with exposure to the sun's harmful radiation. Protection against both UVB and UVA radiation is advocated. Most sunscreens combine chemical UV absorbing sunscreens and physical inorganic sunscreens, which reflect UV, to provide broad-spectrum protection. The correct use of sunscreens should be combined with the avoidance of midday sun and the wearing of protective clothing and glasses, as part of an overall sun protection regimen [70,68]. Unfortunately, inaccurate information is currently roaming the media and the Internet regarding the safety, toxicity, and acute side effects of the active ingredients currently used in sunscreens, therefore discouraging people from using sunscreens [71]. Chemical sunscreens are organic and generally aromatic compounds conjugated with a carbonyl group. They are designed to absorb high-intensity UVR, produce excitation to a higher energy state, and, with the return to the ground state, result in conversion of the absorbed energy into a longer, lower energy wavelength. Chemical sunscreens can be classified based on their portion of UV coverage. Commonly known ingredients for UVB sunscreen protection are Padimate 0, octinoxate, octisalate, octocrylene, and ensulizole. Commonly known Studies reveal that Persistent Pigment Darkening (PPD) to be a stable end point inducible by all the UVA wavelengths, not affected by fluence rate, i.e. a reliable endogenous UVA dosimeter in the skin [72]. Problems associated with chemical sunscreens are: (i) Requires about 20 minutes after application before it starts to work (ii) Chemical sunscreens may cause side effects, such as erythema, edema, and irritation (especially for those who have dry skin with a damaged moisture barrier) due to the multiple ingredients combined in order to achieve broad spectrum UVA and UVB protection (iii) The higher the SPF (such as formulas of SPF 50 or greater), the higher the risk of irritation for sensitive skin types (iv) The protection it offers gets used up more quickly when in direct UV light, so re-application must be more frequent. (v) Increased chance of redness for rosacea-prone skin types because it changes UV rays into heat which can exacerbate flushing (vi) May clog pores for oily skin types [73]. The importance of adequate UVA protection has become apparent in recent years. The United States and Europe have different standards for assessing UVA protection in sunscreen products. The majority of tested sunscreens offered adequate UVA protection according to US Food and Drug Administration guidelines for broad-spectrum status, but almost 
half of the sunscreens tested did not pass standards set in the European Union. UVA sunscreen ingredients are oxybenzone, meradimate, avobenzene, and tetraphthalydine dicamphor sulfonic acid [74,75]. Broad spectrum is a term designed to mean protection from both UVA and UVB. Problems associated with physical sunscreens are: (i) Can rub off, sweat off and rinse off easily, meaning more frequent re-application when outdoors as needed (ii) The physical sunscreen agents impart high opacity to the topical preparation, which makes the formulated creams cosmetically unacceptable and leave a whitish layer on the skin, making some formulas incompatible for medium to dark skin tones (iii) Can be less protective if not applied and re-applied generously and accurately since UV light can get between the sunscreen molecules and get into the skin [73]. There are few reports available on the application of Polymeric Nanoparticles (NPs) of physical and chemical sunscreen ingredients (titanium dioxide, zinc oxide, octyl methoxycinnamate, oxybenzone, octocrylene, and luteolinon) to improve sun protection efficacy. UV-absorbing agents must accumulate within the upper skin layers in order to provide a dense light-absorbing layer and guarantee water resistance. Incorporation of antioxidants could provide additional benefit by scavenging free radicals. Natural polyphenols are attractive in this respect, due to their potential activity as photoprotectans and antioxidants [68]. 


\section{FDA approved sunscreen ingredients: Literature Review}

\section{Aminobenzoic acid}

Aminobenzoic acid is a Vitamin B Complex Member. The chemical classification of aminobenzoic acid is Vitamin B Complex Compounds. In 1943, p-aminobenzoic acid (PABA) was patented. Red petrolatum was used by the United States military as a sunblock during World War II. The initial compounds were primarily ultraviolet B radiation (UVB) blockers as it was to blame for the most observable effect, sunburn [76]. When exposed to light, aminobenzoic acid (para-aminobenzoic acid or PABA) absorbs UV light and emits excess energy via a photochemical reaction that may cause damage to DNA. Because DNA defects contribute to skin cancer, aminobenzoic acid is no longer widely used in sunscreen formulations. Aminobenzoic acid may also increase oxygen uptake at the tissue level and may enhance monoamine oxidase (MAO) activity to promote the degradation of serotonin, which in excess, may lead to fibrotic changes [77]. Aminobenzoates are the most potent UVB absorber but do not absorb UVA. Their use has declined due to para-aminobenzoic acid (PABA) sensitivity. PABA is a very effective UVB filter; however, it was reportedly the most common photoallergen and contact allergen [78] (Figure 8). (See also 5.1. Sunburn and Sunscreen Facts)

\section{Avobenzone}

UVA blockers, considered broad spectrum and have a high efficacy against UVA I ( $>380 \mathrm{~nm}$ ); however, they are very photounstable and lose from $50 \%$ to $90 \%$ of their particles after 1 hour of UV exposure. It is also reported that they degrade the UV filter octinoxate [27,79]. Avobenzone is the most widely used UVA filter in sunscreen lotion and it is prone to degradation in the presence of sunlight/UV radiation, they show a significant skin penetration [80]. 30\% HPCD-Avobenzone system was the most photostable following UVA exposure at various regimens and also enabled photoprotective efficiency in vivo, evidenced by lower levels of sunburn cells and skin edema induction [81]. To overcome the photo-instability of avobenzone, various photostabilizers have been used as additives, including antioxidants such as vitamin C, vitamin E, and ubiquinone. The dual role of glutathione as a skin whitening agent and a photostabilizer of avobenzone may be useful for the development of multipurpose cosmetic lotions. Avobenzone is dibenzoyl methane derivative. It is oil soluble crystalline solid [82,83]. Mesoporous silicas (MSs) containing avobenzone or oxybenzone effectively ameliorated UVA-induced skin disruption and reduced the possible toxicity elicited by percutaneous penetration [80]. Photosensitization by drugs is a problem of increasing importance in modern life. This phenomenon occurs when a chemical substance in the skin is exposed to sunlight. Photosensitizing drugs are reported to cause severe skin dermatitis, and indeed, it is generally advised to avoid sunbathing and to apply sunscreen. In this context, the NSAID diclofenac is a photosensitive drug, especially when administered in topical form. avobenzone provides partial photoprotection to diclofenac from photocyclization to carbazole derivatives [84]. Avobenzone is widely used in various personal care 
products, is present in swimming pools, and is toxic to aquatic organisms. Avobenzone induces mitochondrial dysfunction-mediated apoptosis leading to abnormal placentation during early pregnancy [85]. Avobenzone was more unstable/toxic than octyl p-methoxycinnamate (an organic UV-B filter originally developed in the 1950s, has been one of the most widely used sunscreens for decades) $[86,87]$. Octocrylene helps stabilize avobenzone, which is good, but it is a known endocrine disruptor that also releases free radicals [88] (Figure 9).

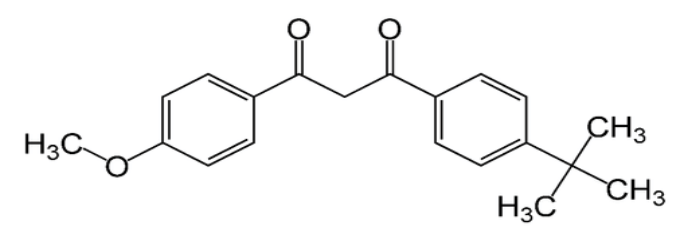

Figure 9: Avobenzone.

\section{Oxybenzone}

Oxybenzone is a benzophenone derivative used as a sunscreen agent. Oxybenzone absorbs UVB and UVA II rays, resulting in a photochemical excitation and absorption of energy [89]. Oxybenzone (Benzophenone-3) is an emerging human and environmental contaminant used in sunscreens and personal care products to help minimize the damaging effects of ultraviolet radiation. The Center for Disease Control (CDC) fourth national report on human exposure to environmental chemicals demonstrated that approximately $97 \%$ of the people tested have oxybenzone present in their urine, and independent scientists have reported various concentrations in waterways and fish worldwide. Oxybenzone can also react with chlorine, producing hazardous by-products that can concentrate in swimming pools and wastewater treatment plants. Moreover, adverse reactions could very well be increased by the closed loop of ingesting fish contaminated with oxybenzone and/or washing the ingredient off our bodies and having it return in drinking water as treatment plants do not effectively remove the chemical as part of their processing protocols. In humans, oxybenzone has been reported to produce contact and photocontact allergy reactions, implemented as a possible endocrine disruptor and has been linked to Hirschsprung's disease. Environmentally, oxybenzone has been shown to produce a variety of toxic reactions in coral and fish ranging from reef bleaching to mortality [90] (Figure 10). (See also 5.1. Sunburn and Sunscreen Facts)

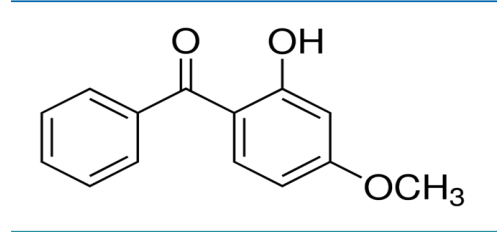

Figure 10: Oxybenzone.

\section{Dioxybenzone}

Dioxybenzone is an approved sunscreen ingredient in concentrations up to 3\% [91]. The benzophenone sunscreens, octabenzone (UV-1) and dioxybenzone (UV-2) were found to exhibit significant chemopreventive activity against mouse skin carcinogenesis which correlated with their antioxidant potency [92]. In a study aimed to qualify photo-safety screening, benzophenone derivatives and ketoprofen exhibited significant reactive oxygen species (ROS) generation upon exposure to simulated sunlight, however ROS generation from sulisobenzone and dioxybenzone was negligible [93]. Polymerization with natural polymer pullulan not only provides a long polymer backbone to dioxybenzone, but also keeps the distance between benzene rings of the dioxybenzone and prevents reduction of photoabsorption intensity. UV/vis spectrophotometry confirmed that dioxybenzone-pullulan polymer and dioxybenzone demonstrated similar UV absorption. Dioxybenzone showed higher plasma concentration after multiple applications compared to that of dioxybenzone-pullulan polymer [94]. Chlorine is used as a chemical disinfectant in swimming pools. Its reactivity suggests sunscreen components might be chlorinated, altering their absorptive and/or cytotoxic properties. Chlorinated oxybenzone and dioxybenzone (caused significantly more cell death than unchlorinated controls. In contrast, chlorination of sulisobenzone actually reduced cytotoxicity of the parent compound. Exposing a commercially available sunscreen product to chlorine also resulted in decreased UV absorbance, loss of UV protection, and enhanced cytotoxicity [95]. Bromal hydrate was also detected as one of the byproducts generated by oxybenzone and dioxybenzone, which is highly toxic, the "positive halogen" properties of bromal hydrate are responsible for its high toxicity [96]. In

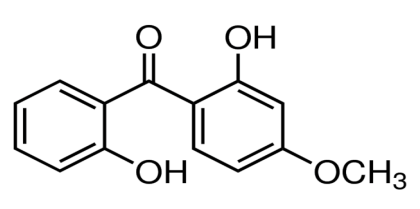


addition to allergic reactions, concerns have been raised about the relative ease of which benzophenone is absorbed into the skin and may promote generation of potentially harmful free radicals [97] (Figure 11).

\section{Cinoxate}

Ester derivatives such as ethylhexyl methoxycinnamate (octinoxate), isoamyl p-methoxycinnamte (amiloxiate), octocrylene and cinoxate are used in cosmetics all over the world as UV filters. However, their maximum concentrations in cosmetic products are restricted due to their adverse effects, which include contact and a photocontact allergies, phototoxic contact dermatitis, contact dermatitis, estrogenic modulation and generation of reactive oxygen species. 4-hydroxycinnamic acid, which is currently indexed as a skin-conditioning cosmetics ingredient, has been widely tested in vitro and in vivo as a new drug candidate for the treatment of hyperpigmentation [98]. Cinnamates have replaced PABA as the next most potent UVB absorber and include octinoxate (OMC) and cinoxate (2-ethoxyethyl-methoxycinnamate). Cinoxate is less commonly used [99]. Major Key players with cinoxate are Major Key Players are Parchem(US), Carbosynth Limited(UK), Synchem UG \& Co. KG(DE) [100] (Figure 12).

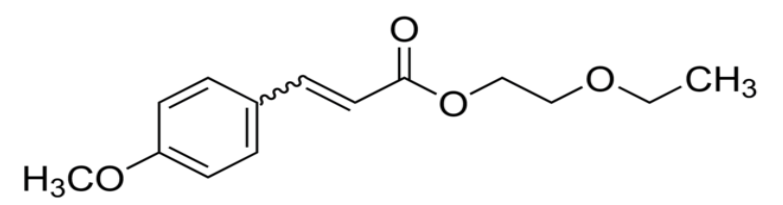

\section{Octinoxate}

Octinoxate (Octyl Methoxycinnamate, OMC) is a cinnamate ester and common ingredient in sunscreen and other skin care products to minimize DNA photodamage. It was originally developed in 1950's as an organic UV-B filter that absorbs UV-B rays from sun. It is often combined with nanoparticles or other waterresistant liposomes in formulations to increase the localization at the epidermis and decrease the risk of percutaneous absorption [101]. OMC is the most commonly used UVB filter in the US. It is not as potent a UVB absorber as padimate 0 ; for this reason, other UVB absorbers are used in combination to increase the SPF. OMC is not very photostable and degrades in the presence of sunlight after a short period of time. OMC is a potent UVB absorber and is the most frequently used sunscreen ingredient. The efficacy of OMC can be further increased when encapsulated in polymethyl methacrylate microsphere [99]. Due to low water solubility ( $<1 \mathrm{mg} / \mathrm{L}$ ), OMC is suitable for most waterproof sunscreen formulations [102]. Hawaii legislature passed a bill that outlaws products that contain Oxybenzone and OMC, effective January 2021. The bill is based on studies that show that oxybenzone may harm coral larvae and that both compounds may "bleach" coral, causing it to lose symbiotic algae [103-105]. OMC has been detected in human urine, blood and breast milk, which indicates that humans are systemically exposed to this compound. OMC is an endocrine disruptor that mimics estrogen and can disrupt thyroid function [106,107] (Figure 13).

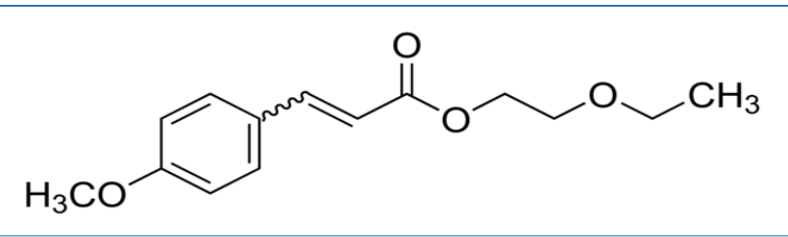

Figure 13: Octinoxate.

\section{Homosalate}

Homomenthyl salicylate or 3,3,5-Trimethylcyclohexyl Salicylate. After topical application of gel, the bioavailability of HMS was $5.4 \pm 1.1$ and $4.2 \pm 0.6 \%$ for high and low doses (10 and $20 \mathrm{mg}$ ), respectively. Homosalate (HMS) is an UV filtering agent used in sunscreens and other cosmetics for skin protection purposes. It is a viscous or light yellow to slightly tan liquid or oil, derives from salicylic acid [108,109]. Salicylates are weak UVB absorbers and they are generally used in combination with other UV filters. Both octisalate and homosalate are water insoluble that leads to their high substantivity, which is the ability to retain its effectiveness after exposure to water and perspiration [110]. HMS does not have endocrine disruptor effects on thyroid function and the pubertal development of female and male rats [111]. Another study says HMS is a potential endocrine disruptor and studies in cells suggest it may impact hormones. In addition to direct health concerns following homosalate exposure, the chemical may also enhance the 
absorption of pesticides in the body [112]. Homosalate suppressed the ear edema response to dinitrobenzene, a possible mechanism of action of the salicylates is suppression of COX [113] (Figure 14).

\section{Octisalate}

Also, Ethylhexyl salicylate, a benzoate ester and a member of phenols. It derives from a salicylic acid. Salicylates are weaker UVB absorbers. It has an approved usage level of 3 to $5 \%$ in both US and EU and is a good solubilizer for benzophenone 3. In suntan lotions,

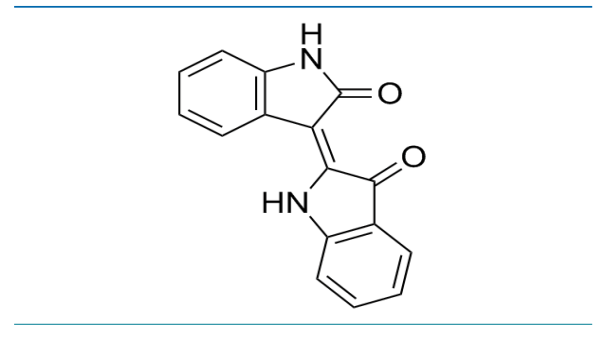

Figure 14: Homosalate (Homomenthyl salicylate). it is used as a preservative and antimicrobial. This salicylate salt is found in wintergreen leaves [114]. They have a long history of use but were supplanted by the more efficient PABA and cinnamate derivatives. They are generally used to augment other UVB absorbers. With the trend to higher SPFs, more octisalate or octyl salicylate (ethylhexyl salicylate) is being used followed by homosalate or homomenthyl salicylate. Both materials have the ability to solubilize oxybenzone and avobenzone [115]. Both homosalate and octisalate were found to suppress experimental autoimmune encephalomyelitis (EAE), a widely used animal model of Multiple sclerosis (MS). Thus, salates may be useful new insight into mechanisms of controlling autoimmune disease [113]<smiles>CCCCC(CC)COC(=O)c1ccccc1O</smiles>

Figure 15: Octisalate (Ethylhexyl salicylate). (Figure 15).

\section{Meradimate (Menthyl Anthranilate)}

Meradimate, before known as menthyl anthranilate, is used in a maximal concentration of $5 \%$ in different products as a UV filter. It is currently required to be named as meradimate in all FDA approved OTC products. Meradimate is approved by the FDA and Health Canada to be used as an ingredient in sunblocking products Meradimate is a monoterpenoid, a broad-spectrum ultraviolet absorber used as a chemical filter in commercial sunscreens [116]. A moderately effective UVA protector not permitted for use in Europe or Japan. Its protective effective action does not cover completely the UVA rays as it only reaches $336 \mathrm{~nm}$. This has been proven even though meradimate has a theoretical protective coverage range between $200-380 \mathrm{~nm}$. Its function is related to the intrinsic structure of meradimate which is an ortho-disubstituted aminobenzoate. This structure allows easy electron delocalization and shifts in the maximum absorption. Poor photoprotection reported by Rodrigues et.al, 2018 makes it a poor choice for an efficient, efficacious sunscreen chemical filter [116-118](Figure 16).<smiles>CC1CCC(C(C)C)C(OC(=O)c2ccccc2N)C1</smiles>

\section{Octocrylene}

2-Ethylhexyl-2-cyano-3,3 diphenylacrylate or octocrylene is chemically related to cinnamates. It can be used to boost SPF and improve water resistance in a given formulation. Octocrylene is photostable and can improve the photostability of other sunscreens. It is expensive and can present difficulties in formulation [115]. The absorption profile of octocrylene spans from 290 to $360 \mathrm{~nm}$ with peak absorption at $307 \mathrm{~nm}$. The compound has an excellent safety profile with low irritation, phototoxicity, and photoallergic potential. Octocrylene may be used in combination with other UV absorbers to achieve higher SPF formulas and to add stability. [99]. Photostability refers to the ability of a molecule to remain intact with irradiation. Photostability is potentially a problem with all UV filters. This issue been raised specifically with avobenzone. This effect may degrade other sunscreens in a formulation, including octyl methoxycinnamate. Octocrylene and some of the newer suncreens, including BEMT, stabilized avobenzone [115]. Chlorination reactions 
showed that only octocrylene was stable in chlorinated seawater [96]. UVA and UVB screening potentials of octocrylene and zinc oxide formulations were compared in the 290-400 nm wavelength region. Zinc oxide loaded SLN suspensions were found to be more effective in the UVA region while octocrylene loaded ones performed better in the UVB region [119]. Octocrylene appears to be a strong allergen leading to contact dermatitis in children and mostly photoallergic contact dermatitis in adults with an often-associated history of photoallergy from ketoprofen. Patients with photoallergy from ketoprofen frequently have positive photopatch test reactions to octocrylene. These patients need to be informed of sunscreen products not containing octocrylene, benzophenone-3, or fragrances [120,121]. The clinical studies show that octocrylene is both a photocontact allergen and a contact allergen [122]. Octocrylene's ability to cause contact allergy is probably attributable to its reactivity towards lysine [123]. A reduction of the UV filter in the formulation packed in HDPE/ LDPE material can occur over time, reducing the protective effect of the product when applied to the skin [124]. Wide application in cosmetics leads to contamination of the aquatic environment, mainly affects transcription of genes related to developmental processes in the brain and liver as well as metabolic processes in the liver (bioaccumulation study in male zebrafish) [125] (Figure

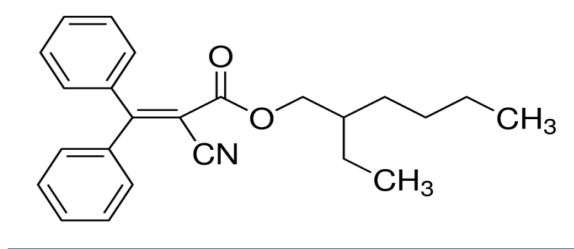

Figure 17: Octocrylene (2-Ethylhexyl-2-cyano-3,3 diphenylacrylate). 17).

\section{Padimate 0}

Padimate $A$ and Padimate $O$ were introduced as substitutes for PABA to reduce the number of reactions seen with PABA. Ethylhexyl dimethyl PABA is also known as padimate 0, OD-PABA, or octyl dimethyl p-aminobenzoate. It is a viscous liquid tends to retain on the surface of the stratum corneum with little penetration. It has a very low potential for sensitization. Ester derivatives of PABA became more popular with greater compatibility in a variety of more substantive vehicles and a lower potential for staining or adverse reactions. Padimate 0 is an active sunscreen agent in cosmetics and over-the-counter sunscreen drug products in concentrations up to $8 \%$, as regulated by the FDA. No irritation was reported when both eyes are washed and left unattended. 5\% ethylhexyl dimethyl PABA mixed with mineral oil applied to rabbit skin did not cause irritation and no skin sensitization in guinea pigs with the same. High concentrations of padimate 0 may be toxic to the epididymis and caution should be exercised when administering this substance to infants younger than six months of age due lack of understanding of its metabolism and absorption. It is widely used as an ingredient in many cosmetics at an average concentration of $1.25 \%$ (0.5-2.0\%) in Korea. It is toxic to the following four organs: testis, epididymis, spleen, and liver. In addition, experiments using human keratinocytes found that ethylhexyl dimethyl PABA inhibits cell growth and DNA synthesis at low concentrations, and halted the cell cycle of malignant melanoma cell line (MM96L) at the G1 phase. According to the EWG database, it is used in many products including lipstick, conditioner, shampoo, anti-aging agents, hair spray, and sunscreen. No significant reproductive toxicity, genotoxicity, carcinogenicity, skin sensitization, skin irritation, or phototoxicity was observed in response to Padimate 0 administration (limited studies there, requires further investigations) [115,126.127] (Figure 18) .

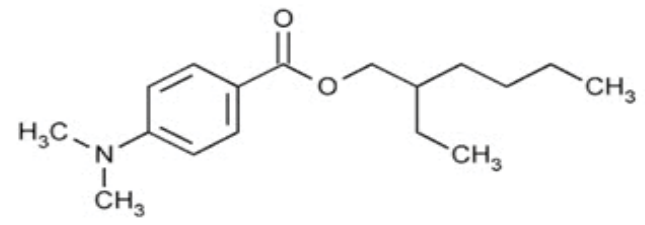

Figure 18: Padimate O (Ethylhexyl dimethyl PABA).

\section{Ensulizole}

2-phenylbenzimidazole-5-sulfonic acid/Phenylbenzimadazole sulfonic acid or ensulizole is a watersoluble UVB absorber that can be used in the water phase of emulsion systems. It is commonly found in cosmetic products and sunscreen formulas in combination with other UV filter compounds due to its minimal protection against UV-A wavelengths, indicated to be used as an UV-B-absorbing molecule in sunscreen formulations. in contrast to most oil-soluble sunscreen ingredients, allowing for a less-greasy, more 
aesthetically pleasing formulation such as a daily use moisturizer containing sunscreen. Phenybenzimidazole sulfonic acid boosts the SPF of organic and inorganic sunscreens. It can also be used in clear gels owing to its water solubility. Due to its water solubility, ensulizole is commonly used in products formulated to feel light and less oily. It was demonstrated by studies that ensulizole treatment provided protection against cyclobutane pyrimidine dimers and photosensitized the formation of oxidized guanine bases after UV-A or UV-B exposure. According to the FDA, the maximal approved concentration of ensulizole is $148 \mathrm{mM}$ although concentrations ranging between 74 and $148 \mathrm{mM}$ can be found in commercial sunscreen products. Ensulizole is capable of generating reactive oxygen species, including singlet oxygen upon photoexcitation. Based on the findings in vitro and in cellulo, ensulizole induces damage on the DNA, causes DNA strand breaks and photosensitizes the formation of oxidized guanines via type I and II photosensitization mechanisms following UV-A or UV-B

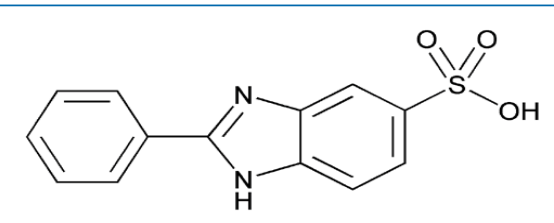

Figure 19: Ensulizole (Phenylbenzimadazole sulfonic acid). irradiation [117, 128-133] (Figure 19).

\section{Sulisobenzone}

A benzophenone does not undergo decomposition to an inactive form if it does not couple to target molecules. Instead, it degrades from the photo-excited state back to its initial state, so it can be once again photolyzed to an active state. This process increases the likelihood that the benzophenone will couple to a target molecule during the photoreaction. Benzophenones are used as photoinitiators, fragrance enhancers, ultraviolet curing agents, and, occasionally, as flavor ingredients; they are also used in the manufacture of insecticides, agricultural chemicals, and pharmaceuticals and as an additive for plastics, coatings, and adhesives. The UV-filter substance Sulisobenzone (BP-4) is widely employed in sunscreens and other personal care products. Sulisobenzone is approved by the FDA in concentrations of up to $10 \%$ and in Canada, is approved by Health Canada at the same concentrations. It works to filter out both UVA and UVB rays, protecting the skin from sun UV damage. The benzophenones are a group of aromatic ketones that have both pharmaceutical and industrial applications. Benzophenones may be found organically in fruits such as grapes, used primarily as a UVA absorber, but boosts SPF values in combination with other UVB absorbers. Sulisobenzone water soluble, somewhat unstable, and used with less frequency. It can cause skin and eye irritation. Does not penetrate the skin to a large degree, but enhances the ability of other chemicals to penetrate. safety use in sunscreen is

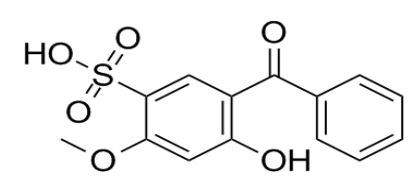

Figure 20: Sulisobenzone (benzophenone-4/BP-4). questionable [118,134-138] (Figure 20).

\section{Trolamine salicylate}

Trolamine salicylate is an organic compound or a salt formed between triethanolamine and salicylic acid. Triethanolamine neutralizes the acidity of the salicylic acid. It is a topical analgesic used for temporary relief of minor pain associated with arthritis, simple backache, muscle strains, sprains, and bruises. Unlike other topical analgesics, trolamine salicylate has no distinct odor which improves patient acceptability. Trolamine or triethanolamine salicylate has good water solubility. It is mostly used for water soluble sunscreens to help increase the SPF of a cosmetics owing to their substantivity to the skin. It also displays low systemic absorption upon dermal or topical administration and has low skin irritant properties. Approved in both the US and Canada, trolamine salicylate is used in concentrations of up to $12 \%$. It filters UVB rays, but has no effect on UVA rays, which means it can't be relied on alone as a sunscreen. It has found to cause photocontact dermatitis $[102,139,140]$ (Figure 21). (See also 5.1. Sunburn and Sunscreen Facts)

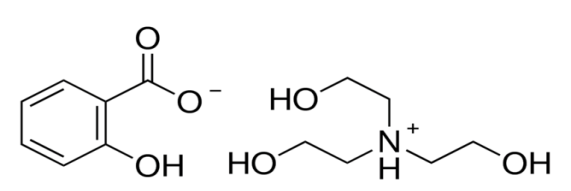




\section{Titanium dioxide}

TiO2 occurs naturally in three crystalline structures: rutile, anatase, and brokite. Rutile is the most common and stable form of this pigment. Important optical properties of this birefringent crystal are its refractive indices in the UV and visible wavelength range. The USP classifies it as a topical protective. The protection is primarily for its opacity due to high refractive index (2.7). However, the high refractive index is not the only property that determines how well a substance blocks light. The film thickness in which the substance is suspended as well as the size of the individual particles also affects the efficacy of the sunscreen. Advantages offered by sunscreens based on inorganic compounds comprise absence of skin irritation and sensitization, inertness of the ingredients, limited skin penetration, and a broad-spectrum protection. As a solar ray protective, it is used in a conc. $5 \%$ to $25 \%$ in ointments and lotions. Since it is not absorbed into the skin, this effect may not be an issue in topical use on unbroken skin. It is also used as a white pigment in cosmetics and paints. According to the US FDA, the protection factor against UVA should be at least onethird of the overall sun protection factor. Previously, TiO2 had a suboptimal cosmetic profile, appearing thick and white on application. Current formulations are micronized or nanoparticle formulations, which blend in with the skin tone and attain better cosmesis. As micro-sized TiO2 is the most effective in UVB and micro-sized ZnO in the UVA range, the combination of the two oxides assures the required broad band UV protection. The particle sizes that result, within human SC, in higher UV absorption and scattering and lower UV transmission improve the UV attenuation. Emulsions are generally unstable, often change from wateroil to oil-water or break down during application on the skin, and may increase the cutaneous permeability. It has been demonstrated that sunscreen TiO2 particles penetrate deeper into human skin from an oily than from an aqueous dispersion. The International Agency for Research on Cancer (IARC) has recently classified TiO2 as an IARC group 2B carcinogen, possibly carcinogenic to humans. The IARC conclusions are based on evidence showing that high concentrations of pigment-grade and ultrafine $\mathrm{TiO} 2$ dust cause respiratory tract cancer in rats. Intrinsic cyto- and genotoxicity of both TiO2 and ZnO NPs (<100 nm) has been frequently reported. Coating the NPs does reduce the toxic effects, especially when silica-based coatings are used, but cannot completely prevent these effects. TiO2, however, has currently attracted more scientific attention than $\mathrm{ZnO}[27,140,141]$.

\section{Zinc oxide}

Sunscreens containing metal oxide nanoparticles appear transparent on the skin and provide excellent protection against sunburn caused by UV radiation. Zinc oxide is a widely used broad-spectrum sunscreen, repeated application of $\mathrm{ZnO}$-NPs to the skin, as used in global sunscreen products, appears to be safe, with no evidence of $\mathrm{ZnO}$-NP penetration into the viable epidermis nor toxicity in the underlying viable epidermis. It was associated with the release and penetration of zinc ions into the skin, but this did not appear to cause local toxicity. In the past two decades, ZnO NPs have become one of the most popular metal oxide nanoparticles in biological applications due to their excellent biocompatibility, economic, and low toxicity. ZnO NPs have emerged a promising potential in biomedicine, especially in the fields of anticancer and antibacterial fields, which are involved with their potent ability to trigger excess ROS production, release zinc ions, and induce cell apoptosis. In addition, ZnO NPs have superior antibacterial, antimicrobial, and excellent UV-blocking properties. ZnO NPs-exposed HepG2 cells presented higher cytotoxicity and genotoxicity, which were associated with cell apoptosis mediated by the ROS triggered mitochondrial pathway. In the brain, the oxidative stress and inflammation reaction were found after ZnO NP exposure and more remarkable changes were identified in aged individual. These kinds of neurotoxicity might due to the destruction of the BBB integrity caused partly by ZnO NPs-induced systemic inflammation [142-145]. 


\section{Sunscreen Formulation}

On the surface, sunscreen products are pretty simple. They consist of a delivery vehicle containing one or more sunscreen active ingredients. When applied to the skin, these sunscreen actives intercept solar UV rays before they can damage the underlying skin. However, while conceptually simple, a detailed analysis reveals that sunscreen formulations are quite complex, requiring careful selection of sunscreen active and vehicle components to control multiple performance and in-use Exhibit 9: Aqueous, Non- Aqueous and Clear Sunscreen Lotion Formulation parameters Exhibit 9.

Alpha-Tocopherol (Filtrosol) has many protective actions, such as decreasing immunosuppression, erythema, photoaging, and photocarcinogenesis [27].

\begin{tabular}{|l|l|l|l|l|l|}
\hline Aqueous Lotion & \multicolumn{3}{|c|}{ Non- Aqueous Lotion } & \multicolumn{3}{|l|}{ Clear Lotion } \\
\hline Ingredients & $\mathbf{( \% )}$ & Ingredients & $\mathbf{( \% )}$ & Ingredients & (\%) \\
\hline Filtrosol B & 7 & Giv-Tan F/Cinoxate & 1.5 & Isobutyl PABA & 5 \\
\hline Methyl Cellulose & 0.5 & Denatured ethyl alcohol & 65 & Tween 20 & 9 \\
\hline Glycerin & 2 & Oleyl alcohol & 10 & Alcohol SD 40 & 45 \\
\hline Ethyl alcohol & 10 & Water & 23 & Water & 41 \\
\hline Water & 80.5 & Perfume & q.s. & & \\
\hline Perfume & q.s. & & & & \\
\hline
\end{tabular}
Naturally occurring vitamin $E$ is not a single compound; instead, vitamin $\mathrm{E}$ is a group of molecules with related structures, some of which may have unique properties in skin. After topical application, vitamin E accumulates not only in cell membranes but also in the extracellular lipid matrix of the stratum corneum, where vitamin E contributes to antioxidant defenses. However, much of a topically applied dose of vitamin E alone will be destroyed in the skin following exposure to UV light. This suggests that although vitamin $\mathrm{E}$ is working as an antioxidant, it is unstable on its own and easily lost from the skin. Thus, improving the stability of topical applications with vitamin E is important [146]. Methyl Cellulose (Methylester of cellulose) is used as an emulsifying, suspending and thickening agent in cosmetics, pharmaceutics and the chemical industry. It's a non-ionic polymer, is highly hydrophilic and thus easily dissolves in cold and hot water [147]. Ethyl alcohol is antimicrobial preservative; disinfectant; skin penetrant; solvent. Cetyl and cetearyl are both derived from coconut and are fatty alcohols. Typically, fatty alcohols are used as emollients and thickeners in skin-care products. Fatty alcohols are not irritating and, in fact, can be beneficial for dry skin. If LMW alcohols are high up on the ingredients list on a bottle of sunscreen then they are going to dry out skin. However, Topical application of $10 \%$ ethanol stimulates the proliferation of peritoneal tissue explants - a semi in-vivo wound model - which can be interpreted as positive influence for stimulation of wound healing by ethanol $[148,149]$. Oleyl alcohol is mainly used in topical pharmaceutical formulations and is generally regarded as a nontoxic and nonirritant material at the levels employed as an excipient. However, contact dermatitis due to oleyl alcohol has been reported. It's an antifoaming agent; dissolution enhancer; emollient; emulsifying agent; skin penetrant; sustained-release agent. SD alcohol 40 is a type of denatured alcohol used in cosmetics and personal care products as an anti-foaming agent, astringent, antimicrobial agent, and a solvent. In addition to SD alcohol 40, the specially denatured alcohols acceptable for use in cosmetics are SD Alcohol 23-A and SD Alcohol 40-B. As an astringent, SD alcohol 40 causes biological tissue to contract or draw together. After topical application, astringents work on proteins called keratins, which function to hold skin cells together to form a barrier. The bonds between keratins are affected by temperature and $\mathrm{pH}$, 
forming only when skin is slightly acidic or cool. If the bonds break, the keratin molecules will separate, causing the outer layer of skin to swell. Astringents cool the skin and cause the bonds to reform. It is this process that produces the temporary toning effect associated with astringents [150]. 2-Ethoxyethyl-pMethoxycinnamate (Giv Tan® F/Cinoxate) used as sunscreen. The most common moisturizing ingredients are occlusive agents which create a barrier that blocks water from escaping the skin. Ingredients like Petrolatum, Mineral Oil and Dimethicone can all be used as occlusive agents. Humectants, which are ingredients that attract water, are also added to lotions. Glycerin is the most commonly used humectant. Finally, emollients are added to improve the feel of the lotion on the skin. They can reduce the tackiness and greasiness caused by the other moisturizing ingredients. Common emollients include coconut oil, cetyl esters, and certain silicones. Sunscreen formulations are typically thinner in viscosity than standard skin lotions [151] Exhibit 10.

\begin{tabular}{|c|c|c|c|c|c|c|c|c|}
\hline \multirow{2}{*}{ Ingredients } & \multicolumn{8}{|c|}{ Quantity (\% w/w) } \\
\hline & Sc1 & Sc2 & SC3 & SC4 & SC5 & SC6 & SC7 & SC8 \\
\hline Oil phase & 25.05 & 25.05 & 25.05 & 25.05 & 25.05 & 25.05 & 25.05 & 25.05 \\
\hline Preservative & 0.03 & 0.03 & 0.03 & 0.03 & 0.03 & 0.03 & 0.03 & 0.03 \\
\hline Aqueous phase & 1.8 & 1.8 & 1.8 & 1.8 & 1.8 & 1.8 & 1.8 & 1.8 \\
\hline Plain morin & - & - & 0.05 & - & - & - & 0.05 & - \\
\hline Avobenzone & - & - & - & - & - & 2.66 & 2.66 & 2.66 \\
\hline Nano titanium dioxide & - & 4.55 & 4.43 & 4.55 & 4.55 & 4.43 & 4.43 & 4.43 \\
\hline Nano zinc oxide & - & 4.55 & 4.43 & 4.55 & 4.55 & 4.43 & 4.43 & 4.43 \\
\hline Morin nanoparticles & - & - & - & - & 0.05 & - & - & 0.05 \\
\hline Plain nanoparticles & - & - & - & 0.05 & - & - & - & - \\
\hline Water (solvent) & to 100 & to 100 & to 100 & to 100 & to 100 & to 100 & to 100 & to 100 \\
\hline
\end{tabular}

Morin is a yellow chemical compound that can be isolated from Maclura pomifera (Osage orange), Maclura tinctoria (old fustic) and from leaves of Psidium guajava (common guava) [152]. Morin is a pentahydroxyflavone that is 7-hydroxyflavonol bearing three additional hydroxy substituents at positions 2 ' 4' and 5. It has a role as an antioxidant, a metabolite, an antihypertensive agent, a hepatoprotective agent, a neuroprotective agent, an anti-inflammatory agent, an antineoplastic agent, an antibacterial agent, an EC 5.99.1.2 (DNA topoisomerase) inhibitor and an angiogenesis modulating agent. It is a pentahydroxyflavone and a 7-hydroxyflavonol [153]. $\mathrm{ZnO}$ and $\mathrm{TiO} 2$ combinations are particularly valuable because of their ability to filter both UVA and UVB radiations, providing broader UVR protection than that observed with individual component [62]. In 2018, the EWG reported that a large increase in these inorganic filters with $\sim 41 \%$ of sunscreens in the United States designated as mineral only. This figure has more than doubled (from 17\%) since 2007 [111][63]. Only two sunscreen active ingredients approved in the US, avobenzone (butylmethoxydibenzoylmethane) and zinc

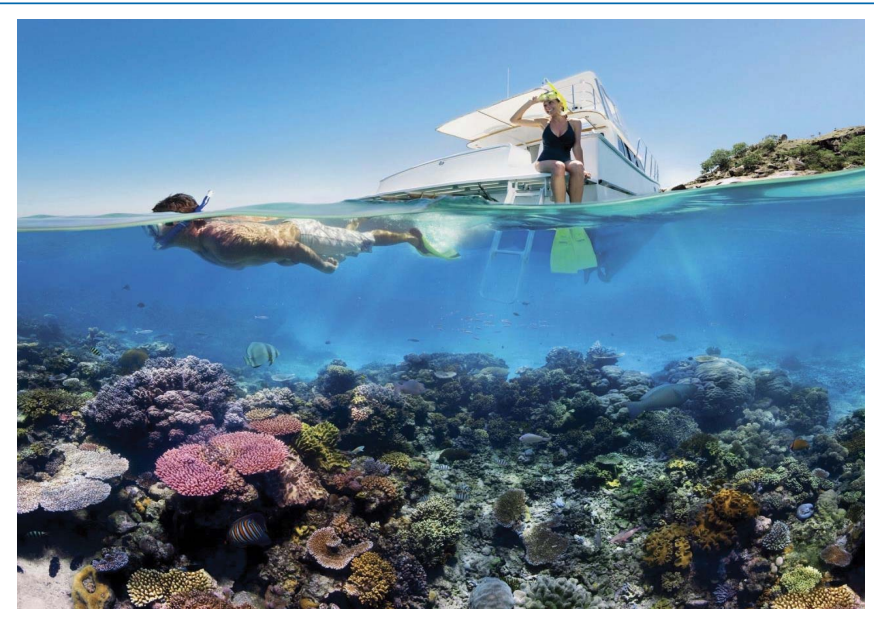

Figure 22: Colorful reefs are a major draw for tourists. But chemicals in sunscreen and ocean warming pose serious threats to them [183]. Studies have shown that oxybenzone and octinoxate are found in over 3,500 sunscreen products, including household names like Tropicana, Banana Boat, and Coppertone. When corals absorb these chemicals, they have a similar reaction as they would if surrounding water temperatures were to get too warm. In addition, the presence of these chemicals in sea water allows viruses to thrive, putting corals at high risk of catching an infection that could lead to bleaching and death.. 
oxide ( $\mathrm{ZnO}$ ), provide true broad-spectrum protection against UVA wavelengths $>360 \mathrm{~nm}$. Although effective against shorter UVR wavelengths $<360 \mathrm{~nm}$, titanium dioxide TiO2 is also often believed to confer broadspectrum protection and is substituted for $\mathrm{ZnO}$ or avobenzone. Use of proper formulation strategies can ensure that avobenzone losses are minimized to the extent that they have no impact on a product's ability to deliver sustained protection, even over periods of prolonged exposure to UVR [154] (Figure 22). 


\section{Sunscreen vs Coral Reef}

While covering less than $1 \%$ of the ocean surface, coral reefs provide habitat for nearly one third of marine fish species as well as $10 \%$ of all fish captured for human consumption. Coral reefs also provide major essential benefits to people, like food production, tourism, biotechnology development, and coastal protection. There is strong evidence that some sunscreen ingredients, especially oxybenzone, are harmful to corals if the concentration in water is high. In some situations, primarily related to the number of swimmers and the geography of the shoreline, concentrations of oxybenzone far exceed the levels shown to be harmful to corals [155]. In 2015, the nonprofit Haereticus Environmental Laboratory surveyed Trunk Bay beach on St. John, where visitors ranged from 2,000 to 5,000 swimmers daily, and estimated over 6,000 pounds of sunscreen was deposited on the reef annually. The same year, it found an average of 412 pounds of sunscreen was deposited daily on the reef at Hanauma Bay, a popular snorkeling destination in Oahu (Hawaii) that draws an average of 2,600 swimmers each day. Over the past three years, one-fifth of the world's coral reefs have died off - and there is a growing awareness that sunscreen is playing a role. From 6,000 to 14,000 tons of sunscreen slide off of humans into coral reef areas each year, exposing the gorgeous underwater ecosystems to chemicals that can kill them. Global warming is the main reason that coral reefs are dying - but sunscreens play a role, too [156]. Danovaro et.al, 2008 revealed that sunscreens, by promoting viral infection, potentially play an important role in coral bleaching in areas prone to high levels of recreational use by humans. Coral bleaching has negative impacts on biodiversity and functioning of reef ecosystems and their production of goods and services. This increasing world-wide phenomenon is associated with temperature anomalies, high irradiance, pollution, and bacterial diseases. Hard-coral bleaching and the increase in viral abundance in seawater were also seen after coral treatment with mitomycin $\mathrm{C}$, an antibiotic commonly used to induce the lytic cycle in latent viral infections [157]. Unfortunately, the World Conservation Institute estimates that $20 \%$ of coral reefs are already destroyed, another $25 \%$ are in great immediate threat, and another $25 \%$ will be threatened by 2050 [158-185].

\section{Epilogue}

The skin stratum corneum acts as a barrier that isolates the organism from the environment and avoids water loss from tissues. Such a sealed sheath is essential for the physiological processes of the skin and of the entire body, but poses problems for the topical delivery of substances to the tissues. This kind of hindrance has been known since ancient times and has been empirically approached, e.g., by the use of greasy or oily materials in skin care applications. Technological achievements in the topical administrations of medicaments and in skin care products have led to the development of vehicles and penetration enhancer and to the design of technologically advanced formulations. Although synthetic chemical structures have been abundantly used in this field, traditional practices and scientific studies have shown through the years that botanical sources can provide all kinds of elements for vehiculating drugs and active compounds and for enhancing their permeation through the skin. There is wide variability in price, SPF protection, and product claims among commercially available sunscreens. Cosmetic elegance is one of the most important positive features, followed by product performance. Dermatologists should counsel patients that sunscreen products come with numerous marketing claims and varying cosmetic applicability, all of which must be balanced with adequate photoprotection. In addition, consumers should be advised to select a product 
with broad-spectrum coverage, an SPF of 30 or higher, and water and/or sweat resistance in the setting of water activities or high ambient temperatures. UV filters are analyzed in their pure form by ingredient suppliers and also by cosmetic companies that purchase those filters for incorporation into their finished products. Once these UV filters are included into cosmetic finished products, they also need to be analyzed for both quality control and regulatory compliance. Use of sun screening agents is beneficial in minimizing the occurrence of skin cancers in people with fair skin. However, the same effect on Asian skin is debatable, as this skin type is considered to be resistant to skin cancers. Sunscreen use is advisable in young adults to prevent and minimize other photodamaging effects. Affordability and proper application techniques are the challenges that must be addressed in order to achieve regular sunscreen usage. 


\section{Article Summary}

Promoting sunscreen use is an integral part of prevention programs aimed at reducing UV radiationinduced skin damage and skin cancers. Protection against both UVB and UVA radiation is advocated. Despite the efforts of physicians and regulatory authorities to spread awareness regarding sunburn, skin cancer, and the benefits of regularly using sun screening agents, treatment adherence is low. Providing cosmetically acceptable preparations and educating people about following the application instructions, is a challenge often faced by treating physicians. Pricing sunscreens reasonably and making them water resistant and non-sticky are a few of the challenges faced by manufacturers. Manufacturers must also consider sensitization reactions, especially in those having eczema or photo dermatoses. Sun protection factor (SPF) is affected by application density, water resistance and other factors. An adequate SPF for an individual should be balanced to skin phenotype and exposure habits. The correct use of sunscreens should be combined with the avoidance of midday sun and the wearing of protective clothing and glasses, as part of an overall sun protection regimen. The FDA approved sunscreen ingredients are extensively reviewed. A clear and straightforward recommendation on their safety and efficacy still remains a big challenge. 


\section{References}

1. Dale Wilson B, Moon S, Armstrong F (2012) Comprehensive review of ultraviolet radiation and the current status on sunscreens. J Clin Aesthet Dermatol 5: 18-23. Link: https:// tinyurl.com/y3yyxvc9

2. Sivamani RK, Crane LA, Dellavalle RP (2009) The benefits and risks of ultraviolet tanning and its alternatives: the role of prudent sun exposure. Dermatol Clin 27: 149-1454. Link: https://tinyurl.com/yxg3w6s4

3. Pinto I, Bogi A, Picciolo F, Stacchini N, Buonocore G, et al. (2015) Blue Light and Ultraviolet Radiation Exposure from Infant Phototherapy Equipment. J Occup Environ Hyg 12: 603-610. Link: https://tinyurl.com/y4aywzz6

4. de Groot T, Chowdhary A, Meis JF, Voss A(2019) Killing of Candida auris by UV-C: Importance of exposure time and distance. Mycoses 62: 408-412. Link: https://tinyurl.com/ y3zszm5r

5. Dai T, Kharkwal GB, Zhao J, St Denis TG, Wu Q, et al. (2011) Ultraviolet-C light for treatment of Candida albicans burn infection in mice. Photochem Photobiol 87: 342-349. Link: https://tinyurl.com/y2vhuxub

6. Nussbaumer B, Kaminski-Hartenthaler A, Forneris CA, Morgan LC, Sonis JH, et al. (2015) Light therapy for preventing seasonal affective disorder. Cochrane Database Syst Rev 11: CD011269. Link: https://tinyurl. com/y43m3zof

7. Lam RW, Levitt AJ, Levitan RD, Michalak EE, Cheung AH, et al. (2016) Efficacy of Bright Light Treatment, Fluoxetine, and the Combination in Patients with Nonseasonal Major Depressive Disorder: A Randomized Clinical Trial. JAMA Psychiatry 73: 56-63. Link: https://tinyurl.com/y5sny6fb

8. Budzowski A Sunburn vs Sun Poisoning. Web UPMC MyHealth Matters. Link: https://tinyurl.com/y34t4t4g

9. Moan J, Grigalavicius M, Dahlback A, Baturaite Z, Juzeniene A (2014) Ultraviolet-radiation and health: optimal time for sun exposure. Adv Exp Med Biol 810: 423-428. Link: https://tinyurl.com/y2oyjx47

10. Guerra KC, Crane JS (2019) Skin Cancer Prevention. StatPearls [Internet]. Link: https://tinyurl.com/yyj4v9vq

11. (2018) Sunburn (Sun Poisoning) Symptoms, Pain Relief, and Healing Time. Medicine Net. Link: https://tinyurl.com/ y2rbgcsp

12. (2012) Get Rid of Sunburn Fast: Pain Relief, Blisters,Peeling,
Home Remedies. Medicine Net. Link: https://tinyurl.com/ yxotd57b

13. Koh D, Wang H, Lee J, Chia KS, Lee HP, et al. (2003) Basal cell carcinoma, squamous cell carcinoma and melanoma of the skin: analysis of the Singapore Cancer Registry data 1968-97. Br J Dermatol 148: 1161-1166. Link: https:// tinyurl.com/yyp53scf

14. Amaro-Ortiz A, Yan B, D'Orazio JA (2014) Ultraviolet radiation, aging and the skin: prevention of damage by topical cAMP manipulation. Molecules 19: 6202-6219. Link: https://tinyurl.com/y6m5fat2

15. Amblard P, Leccia MT (1992) [Skin diseases with photosensitivity]. Rev Prat 42: 1365-1368. Link: https:// tinyurl.com/yxtjmzwy

16. Zuba EB, Koronowska S, Osmola-Mańkowska A Jenerowicz D (2016) Drug-induced Photosensitivity. Acta Dermatovenerol Croat 24: 55-64. Link: https://tinyurl.com/ yxb685k7

17. Web MD. Sun Poisoning. Link: https://tinyurl.com/y63ttdbu

18. Golmohammadzadeh $\mathrm{S}$, Imani $\mathrm{F}$, Hosseinzadeh $\mathrm{H}$, Jaafari MR (2011) Preparation, characterization and evaluation of sun protective and moisturizing effects of nanoliposomes containing safranal. Iran J Basic Med Sci 14: 521-533. Link: https://tinyurl.com/y6lecmew

19. Opene C, Chren MM, Linos E (2017) Types of Shade Vary in Protection Just Like Sunscreens. JAMA Dermatol 153: 1070-1071. Link: https://tinyurl.com/y5sz8zln

20. Wolf R, Matz H, Orion E, Lipozencić J (2003) Sunscreens-the ultimate cosmetic. Acta Dermatovenerol Croat 11: 158162. Link: https://tinyurl.com/yyeu8v9s

21. Rego D, Fernandes L, Nascimento T, Grenha A (2010) Evaluation of a sunscreen during a typical beach period. J Pharm Bioallied Sci 2: 47-50. Link: https://tinyurl.com/ y2qz3g5j

22. Ruszkiewicz JA, Pinkas A, Ferrer B, Peres TV, Tsatsakis A, et al. (2017) Neurotoxic effect of active ingredients in sunscreen products, a contemporary review. Toxicol Rep 4: 245-259. Link: https://tinyurl.com/y33xzapu

23. Kannan S, Lim HW (2014) Photoprotection and vitamin D: a review. Photodermatol Photoimmunol Photomed. 30: 137145. Link: https://tinyurl.com/y56sdhf5 
24. Pandika M (2018) Looking to Nature for New Sunscreens. ACS Cent Sci 4: 788-790. Link: https://tinyurl.com/ y4y6heye

25. (2019) Sunscreen: How to Help Protect Your Skin from the Sun. Web US FDA. Link: http://tiny.cc/6jhjaz

26. Only TWO of the 16 ingredients in sunscreen are definitely safe, FDA declares: Two other chemicals will be banned as the agency demands more research on the other 12. Link: https://tinyurl.com/y34t9ar7

27. Gabros S, Zito PM (2019) Sunscreens and Photoprotection. StatPearls [Internet]. Link: https://tinyurl.com/y6h97pxp

28. Preidt R (2019) FDA aims to strengthen sunscreen rules Medical Press (Health). Link: https://tinyurl.com/y6l22bjs

29. Maddipatla M (2019) U.S. FDA proposes new regulations for over-the-counter sunscreens. Reuters. Link: https:// tinyurl.com/y388brjd

30. Ripamonti E, Allifranchini E, Todeschi S, Bocchietto E (2018) Endocrine Disruption by Mixtures in Topical Consumer Products. Cosmetics 5: 61. Link: http://tiny.cc/aihjaz

31. Raffa RB, Pergolizzi JV, Taylor R, Kitzen JM (2018) Sunscreen bans: Coral reefs and skin cancer. J Clin Pharm Ther 44: 134-139. Link: https://tinyurl.com/y358ozdz

32. Guerra KC, Crane JS (2019) Sunburn. StatPearls [Internet]. Link: https://tinyurl.com/y3woe24a

33. McStay CM (2018) What is the pathophysiology of sunburn? Medscape. Link: https://tinyurl.com/yywhze7w

34. Latha MS, Martis J, Shobha V, Sham Shinde R, Bangera S, et al. (2013) Sunscreening agents: a review. J Clin Aesthet Dermatol 6: 16-26. Link: https://tinyurl.com/y3dy4aec

35. Mackiewicz-Wysocka $M$, Bowszyc-Dmochowska $M$ Strzelecka-Węklar D, Dańczak-Pazdrowska A, Adamski Z (2013) Basal cell carcinoma - diagnosis. Contemp Oncol (Pozn) 17: 337-42. Link: https://tinyurl.com/yyddr88j

36. Kumar R, Deep G, Agarwal R(2015) An Overview of Ultraviolet B Radiation-Induced Skin Cancer Chemoprevention by Silibinin. Curr Pharmacol Rep 1: 206-215. Link: https:// tinyurl.com/yyh4c5c6

37. Guy GP, Thomas CC, Thompson T, Watson M, Massetti GM, et al. (2015) Vital signs: melanoma incidence and mortality trends and projections - United States, 1982-2030. MMWR Morb Mortal Wkly Rep 64: 591-596. Link: https://tinyurl. com/yyg9ne9h

38. Sample A, He YY (2018) Mechanisms and prevention of UV-induced melanoma. Photodermatol Photoimmunol Photomed 34: 13-24. Link: https://tinyurl.com/y6tfnoss

39. Cho BA, Yoo SK, Seo JS (2018) Signatures of photo-aging and intrinsic aging in skin were revealed by transcriptome network analysis. Aging 10: 1609-1626. Link: https://bit. ly/2YjZbsX

40. Bosch R, Philips N, Suárez-Pérez JA, Juarranz A, Devmurari A, et al. (2015) Mechanisms of Photoaging and Cutaneous Photocarcinogenesis, and Photoprotective Strategies with
Phytochemicals. Antioxidants (Basel) 4: 248-268. Link: https://bit.ly/2SWeQJ9

41. Kang S, Fisher GJ, Voorhees JJ (2001) Photoaging: pathogenesis, prevention, and treatment. Clin Geriatr Med 17: 643-659. Link: https://bit.ly/2SWz050

42. Han A, Chien AL, Kang S (2014) Photoaging. Dermatol Clin 32: 291-299. Link: https://bit.ly/2ZnAhVN

43. Masnec SI, Poduje S (2008) Photoaging. Coll Antropol 2: 177-80. Link: https://bit.ly/2YiRMda

44. Mukherjee S, Date A, Patravale V, Korting HC, Roeder A, et al. (2006) Retinoids in the treatment of skin aging: an overview of clinical efficacy and safety. Clin Interv Aging 1 : 327-348. Link: https://bit.ly/2X39uvR

45. Pandel R, Poljšak B, Godic A, Dahmane R (2013) Skin photoaging and the role of antioxidants in its prevention. ISRN Dermatol 2013: 930164. Link: https://bit.ly/2YfgjQo

46. Dhaliwal S, Rybak I, Ellis SR, Notay M, Trivedi $M$, et al. (2019) Prospective, randomized, double-blind assessment of topical bakuchiol and retinol for facial photoageing. $\mathrm{Br} J$ Dermatol 180: 289-296. Link: https://bit.ly/2YzDDry

47. Driscoll MS, Wagner RF (2000) Clinical management of the acute sunburn reaction. Cutis 66: 53-58. Link: https:// tinyurl.com/yye 5cwxp

48. Faurschou A, Wulf HC (2008) Topical corticosteroids in the treatment of acute sunburn: a randomized, double-blind clinical trial. Arch Dermatol 144: 620-624. Link: https:// tinyurl.com/y4vq8zcm

49. Feily A, Namazi MR (2009) Aloe vera in dermatology: a brief review. G Ital Dermatol Venereol 144: 85-91. Link: https:// tinyurl.com/yyje4ft7

50. Puvabanditsin P, Vongtongsri R (2005) Efficacy of aloe vera cream in prevention and treatment of sunburn and suntan. J Med Assoc Thai 4: S173-176. Link: https://tinyurl. com/y2bvp983

51. Tadicherla S, Berman B (2006) Percutaneous dermal drug delivery for local pain control. Ther Clin Risk Manag 2: 99 113. Link: https://tinyurl.com/yyv69n2h

52. Das LM, Binko AM, Traylor ZP, Peng H, Lu KQ (2019) Vitamin $D$ improves sunburns by increasing autophagy in M2 macrophages. Autophagy 15: 813-826. Link: https:// tinyurl.com/y4tp5lt8

53. Moore DE (2002) Drug-induced cutaneous photosensitivity: incidence, mechanism, prevention and management. Drug Saf 25: 345-372. Link: https://tinyurl.com/y66p2b34

54. Drucker AM, Rosen CF (2011)Drug-induced photosensitivity: culprit drugs, management and prevention. Drug Saf 34 : 821-837. Link: https://tinyurl.com/y2c3h3nt

55. Harth Y, Rapoport M (1996) Photosensitivity associated with antipsychotics, antidepressants and anxiolytics. Drug Saf 14: 252-259. Link: https://tinyurl.com/y3ue5tqe

56. Pile HD, Nicolas D (2019) Isotretinoin. StatPearls [Internet]. Link: https://tinyurl.com/y5umphac 
57. Hodgkiss-Harlow CJ, Eichenfield LF, Dohil MA (2011) Effective monitoring of isotretinoin safety in a pediatric dermatology population: a novel "patient symptom survey" approach. J Am Acad Dermatol 65: 517-524. Link: https:// tinyurl.com/y6sjxltz

58. Volkovova K, Bilanicova D, Bartonova A, Letašiová S, Dusinska M (2012) Associations between environmental factors and incidence of cutaneous melanoma. Review. Environ Health 11: S12. Link: https://tinyurl.com/y2egwrr3

59. Sivamani RK, Crane LA, Dellavalle RP (2009) The benefits and risks of ultraviolet tanning and its alternatives: the role of prudent sun exposure. Dermatol Clin 27: 149-154. Link: https://bit.ly/2YujNde

60. Juzeniene A, Moan J(2012) Beneficial effects of UV radiation other than via vitamin $D$ production. Dermatoendocrinol 4 : 109-117. Link: https://bit.ly/2YzPSA8

61. Choi W, Miyamura Y, Wolber R, Smuda C, Reinhold W, et al. (2010) Regulation of human skin pigmentation in situ by repetitive UV exposure: molecular characterization of responses to UVA and/or UVB. J Invest Dermatol 130: 1685-1696. Link: https://bit.ly/2KfUdDL

62. Brenner M, Hearing VJ (2008) The protective role of melanin against UV damage in human skin. Photochem Photobiol 84: 539-549. Link: https://bit.ly/2Yi9e1M

63. Hwang YJ, Park HJ, Hahn HJ, Kim JY, Ko JH, et al. (2011) Immediate pigment darkening and persistent pigment darkening as means of measuring the ultraviolet A protection factor in vivo: a comparative study. $\mathrm{Br} \mathrm{J}$ Dermatol 164: 1356-1361. Link: https://bit.ly/2YBVuya

64. Del Bino S, Duval C, Bernerd F (2018) Clinical and Biological Characterization of Skin Pigmentation Diversity and Its Consequences on UV Impact. Int J Mol Sci 19: E2668. Link: https://bit.ly/336HTy3

65. Holman DM, Fox KA, Glenn JD, Guy GP, Watson M, et al. (2013) Strategies to reduce indoor tanning: current research gaps and future opportunities for prevention. Am J Prev Med 44: 672-681. Link: https://bit.ly/2YEaOtW

66. Grand View Research. U.S. Sun Care Market Size, Share, Industry Trends Report, 2018-2025. Link: https://bit. ly/2LSE7mJ

67. (2018) Sunscreen Manufacturing Industry in the US. IBIS World. Link: https://bit.ly/318qT8Q

68. Shetty PK, Venuvanka V, Jagani HV, Chethan GH, Ligade VS, et al. (2015) Development and evaluation of sunscreen creams containing morin-encapsulated nanoparticles for enhanced UV radiation protection and antioxidant activity. Int J Nanomedicine 10: 6477-6491. Link: https://tinyurl. com/yylb64fv

69. Schneider SL, Lim HW (2018) A review of inorganic UV filters zinc oxide and titanium dioxide. Photodermatol Photoimmunol Photomed. Link: https://bit.ly/2YyLXba

70. Moloney FJ, Collins S, Murphy GM (2002) Sunscreens: safety, efficacy and appropriate use. Am J Clin Dermatol 3: 185-191. Link: https://tinyurl.com/yyz2skvl
71. Jallad KN (2017) Chemical characterization of sunscreens composition and its related potential adverse health effects. J Cosmet Dermatol 16: 353-357. Link: https:// tinyurl.com/y4jz46dp

72. Moyal D, Chardon A, Kollias N (2000) UVA protection efficacy of sunscreens can be determined by the persistent pigment darkening (PPD) method. (Part 2). Photodermatol Photoimmunol Photomed 16: 250-255. Link: https://tinyurl. $\mathrm{com} / \mathrm{y} 289 \mathrm{q} 7 \mathrm{gl}$

73. Desjarlais D (2016) Protecting Your Skin. Chemical vs Physical (Mineral) Sunscreens: Pros and Cons. Link: https://tinyurl.com/yyhwpgty

74. Wang SQ, Xu H, Stanfield JW, Osterwalder U, Herzog B (2011) Comparison of ultraviolet A light protection standards in the United States and European Union through in vitro measurements of commercially available sunscreens. J Am Acad Dermatol 77: 42-47. Link: https:// tinyurl.com/y29zbjs2

75. Schalka S, Naranjo Ravelli F, Perim N, Vasconcelos R (2017) Chemical and Physical Sunscreens. Issa M, Tamura B (eds) Daily Routine in Cosmetic Dermatology. Clinical Approaches and Procedures in Cosmetic Dermatology. Link: https://tinyurl.com/yy83oywk

76. Tahiliani S, Shirolikar M (2018) Viva voce on sunscreens. Indian J Drugs Dermatol 4: 92-96. Link: https://tinyurl.com/ yxwujm6c

77. National Center for Biotechnology Information. PubChem. Link: https://tinyurl.com/yylcolzo

78. Kullavanijaya P, Lim HW (2005) Photoprotection. J Am Acad Dermatol 52: 937-958. Link: https://tinyurl.com/ y6a7rf3l

79. Begoun P (2004) The Complete Beauty Bible: The Ultimate Guide to Smart Beauty. Rodale Pr 132. Link: https://tinyurl. com/yynps66w

80. Lin YC, Lin CF, Alalaiwe A, Wang PW, Fang YP, et al. (2018) UV filter entrapment in mesoporous silica hydrogel for skin protection against UVA with minimization of percutaneous absorption. Eur J Pharm Sci 122: 185-194. Link: https:// tinyurl.com/y4p5mgop

81. Ainbinder D, Touitou E (2009) Chapter 44. Skin Photodamage Prevention: State-of-the-art and new prospects. Textbook of Aging Skin 436 Link: https://tinyurl. com/yxuf4ktn

82. (2019) Avobenzone National Center for Biotechnology Information. PubChem. Link: https://tinyurl.com/y6rpw5ag

83. Nash JF, Tanner PR (2005) Chapter 9. Sunscreens. In: Draelos ZD, Thaman LA (2005) Cosmetic Formulation of Skin Care Products. 139. Link: https://tinyurl.com/y46t7dbj

84. Aparici-Espert I, Miranda MA, Lhiaubet-Vallet V (2018) Sunscreen-Based Photocages for Topical Drugs: A Photophysical and Photochemical Study of A DiclofenacAvobenzone Dyad. Molecules 23: E673. Link: https:// tinyurl.com/y6h49hu6

85. Yang C, Lim W, Bazer FW, Song G (2018) Avobenzone 
suppresses proliferative activity of human trophoblast cells and induces apoptosis mediated by mitochondrial disruption. Reprod Toxicol 81: 50-57. Link: https://tinyurl. com/y3ow9d53

86. Uco DP, Leite-Silva VR, Silva HDT, Duque MD, Grice J, et al. (2018) UVA and UVB formulation phototoxicity in a three-dimensional human skin model: Photodegradation effect. Toxicol In Vitro 53: 37-44. Link: https://tinyurl.com/ y46vwjbz

87. Monteiro MS, Ozzetti RA, Vergnanini AL, de BritoGitirana L, Volpato NM, et al. (2012) Evaluation of octyl p-methoxycinnamate included in liposomes and cyclodextrins in anti-solar preparations: preparations, characterizations and in vitro penetration studies. Int $J$ Nanomedicine 7: 3045-3058. Link: https://tinyurl.com/ y3ado2y4

88. De Coster S, van Larebeke N (2012) Endocrine-disrupting chemicals: associated disorders and mechanisms of action. J Environ Public Health 2012: 713696. Link: https:// tinyurl.com/yys95r9a

89. (2019) Oxybenzone. National Center for Biotechnology Information. PubChem Database. Link: https://bit. ly/2ysfBjB

90. DiNardo JC, Downs CA (2018) Dermatological and environmental toxicological impact of the sunscreen ingredient oxybenzone/benzophenone-3. J Cosmet Dermatol 17: 15-19. Link: https://bit.ly/2SViqmA

91. Fediuk DJ (2012) Pharmacokinetic and Toxicological Characterization of Repellent DEET and Sunscreen Oxybenzone. Link: https://tinyurl.com/y6xgna7r

92. Rao GS, Tokuda H, Ichiishi E, Takasaki M, lida A, et al. (2013) Oral chemoprevention of skin cancer in mice by benzophenone sunscreens dioxybenzone and octabenzone in drinking water. Anticancer Res 33: 2535-2540. Link: https://tinyurl.com/y6ova387

93. Seto $Y$, Ohtake $H$, Kato $M$, Onoue $S$ (2015) Phototoxic Risk Assessments on Benzophenone Derivatives: Photobiochemical Assessments and Dermal CassetteDosing Pharmacokinetic Study. J Pharmacol Exp Ther 354: 195-202. Link: https://tinyurl.com/yx8vdmd2

94. Heo S, Hwang HS, Jeong $Y$, Na K (2018) Skin protection efficacy from UV irradiation and skin penetration property of polysaccharide-benzophenone conjugates as a sunscreen agent. Carbohydr Polym 195: 534-541. Link: https://tinyurl. com/y4of6f8h

95. Sherwood VF, Kennedy S, Zhang H, Purser GH, Sheaff RJ (2012) Altered UV absorbance and cytotoxicity of chlorinated sunscreen agents. Cutan Ocul Toxicol 31: 273279. Link: https://tinyurl.com/y6sdjcet

96. Butler TC (1948) Bromal Hydrate and Chloral Hydrate: A Pharmacological Contrast And Its Chemical Basis. J Pharmacol Exp Ther 94: 401-411. Link: https://tinyurl.com/ y4rwmmlp

97. Ngan V (2012) Allergy to benzophenone. Web DermNet NZ. Link: https://tinyurl.com/y2yz4bab
98. Gunia-Krzyżak A, Słoczyńska K, Popiół J, Koczurkiewicz $\mathrm{P}$, Marona $\mathrm{H}$, et al. (2018) Cinnamic acid derivatives in cosmetics: current use and future prospects. Int $\mathrm{J}$ Cosmet Sci 40: 356-366. Link: https://tinyurl.com/y2b5967h

99. Rai R, Shanmuga SC, Srinivas C (2012) Update on photoprotection. Indian J Dermatol. 57: 335-342. Link: https://tinyurl.com/y2z7snxb

100. (2019) Cinoxate Market is Likely to Witness huge Growth - Major Key Players are Parchem(US), Carbosynth Limited(UK), Synchem UG \& Co. KG(DE). Market Research Gazette.. Link: https://bit.ly/2YAEjwL

101. 2019) Octinoxate. National Center for Biotechnology Information. PubChem Database. Link: https://bit. ly/2GEjNkW

102. Lim HW, Thomas L, Rigel DS (2004) Chapter 6 . Photoprotection. Rigel DS, Weiss RA, Lim HW, Dover JS (2004) Photoaging Basic and Clinical Dermatology. CRC Press. Link: https://tinyurl.com/y552k34z

103. Molecule of the Week Archive. In a few years, coral in Hawaiian waters will no longer have to put up with us. What molecules are we? Web ACS, July 16, 2018. Link:

104. Siller A, Blaszak SC, Lazar M, Olasz Harken E (2018) Update About the Effects of the Sunscreen Ingredients Oxybenzone and Octinoxate on Humans and the Environment. Plast Surg Nurs 38: 158-161. Link: https:// bit.ly/315DycH

105. Raffa RB, Pergolizzi JV, Taylor R, Kitzen JM (2019) NEMA Research Group. Sunscreen bans: Coral reefs and skin cancer. J Clin Pharm Ther 44: 134-139. Link: https://bit. ly/2MwN44K

106. Axelstad M, Boberg J, Hougaard KS, Christiansen S, Jacobsen PR, et al. (2011) Effects of pre- and postnatal exposure to the UV-filter octyl methoxycinnamate (OMC) on the reproductive, auditory and neurological development of rat offspring. Toxicol Appl Pharmacol 250: 278-290. Link: https://bit.ly/2YfBNwB

107. Darbre PD (2006_ Environmental oestrogens, cosmetics and breast cancer. Best Pract Res Clin Endocrinol Metab 20: 121-143. Link: https://bit.ly/2YfJQJT

108. (2019) Homosalate National Center for Biotechnology Information. PubChem. Link: https://tinyurl.com/ y58n98nd

109. Kim TH, Shin BS, Kim KB, Shin SW, Seok SH, et al. (2014) Percutaneous absorption, disposition, and exposure assessment of homosalate, a UV filtering agent, in rats. J Toxicol Environ Health 77: 202-213. Link: https://tinyurl. com/y3wzm9lg

110. Kullavanijaya P, Lim HW (2005) Photoprotection. J Am Acad Dermatol 52: 937-958. Link: https://tinyurl.com/ y6a7rf3l

111. Erol M, Çok I, Bostan Gayret Ö, Günes P, Yigit Ö, et al. (2017) Evaluation of the endocrine-disrupting effects of homosalate (HMS) and 2-ethylhexyl 4-dimethylaminobenzoate (OD-PABA) in rat pups during the prenatal, lactation, and early postnatal periods. Toxicol

Ābdul Kader Mohiuddin, Bangladesh ISBN: 978-81-943057-1-2
Peertechz Publications Inc. 
Ind Health 33: 775-791. Link: https://tinyurl.com/y2lojcte

112. Homosalate. Link: https://tinyurl.com/y3vyp32o

113. Wang Y, Marling SJ, Plum LA, DeLuca HF (2017) Salate derivatives found in sunscreens block experimental autoimmune encephalomyelitis in mice. Proc Natl Acad Sci 114: 8528-8531. Link: https://bit.ly/20AcUY0

114. Michalun MV, DiNardo JC (2014) Skin Care and Cosmetic Ingredients Dictionary. Cengage Learning. Link: https:// bit.ly/2YAY839

115. Levy SB (2009) Chapter 29. UV Filters. In: André O. Barel, Marc Paye, Howard I. Maibach. Handbook of Cosmetic Science and Technology. CRC Press. Link: https://bit. ly/2SUOgjv

116. Rodrigues NDN, Cole-Filipiak NC, Blodgett KN, Abeysekera C, Zwier TS, et al. (2018) Wavepacket insights into the photoprotection mechanism of the UV filter methyl anthranilate. Nat Commun 9: 5188. Link: https://tinyurl. com/yyobh $4 x x$

117. Wolverton SE (2007) Comprehensive Dermatologic Drug Therapy, 3rd Edition. Elsevier Health Sciences. Link: https://tinyurl.com/y2qv3ggr

118. James MG, Anderson BE, DeLeo VA (2016) Contact \& Occupational Dermatology. JP Medical Ltd. Link: https:// tinyurl.com/y2zxm5zo

119. Avenel-Audran $M$, Dutartre $H$, Goossens $A$, Jeanmougin M, Comte C, et al. (2010) Octocrylene, an emerging photoallergen. Arch Dermatol 146: 753-757. Link: https:// bit.ly/2GCPj2I

120. de Groot AC, Roberts DW (2014) Contact and photocontact allergy to octocrylene: a review. Contact Dermatitis 70: 193-204. Link: https://bit.ly/2YyKMIM

121. Berkman MS, Yazan Y (2012) Solid lipid nanoparticles: a possible vehicle for zinc oxide and octocrylene. Pharmazie 67: 202-208. Link: https://bit.ly/2YjVbbV

122. Manová E, von Goetz N, Hungerbühler K (2014) Ultraviolet filter contact and photocontact allergy: consumer exposure and risk assessment for octocrylene from personal care products and sunscreens. $\mathrm{Br} \mathrm{J}$ Dermatol 171: 1368-1374. Link: https://bit.ly/31bPJF5

123. Karlsson I, Vanden Broecke $\mathrm{K}$, Mårtensson J, Goossens A, Börje A (2011) Clinical and experimental studies of octocrylene's allergenic potency. Contact Dermatitis 64: 343-352. Link: https://bit.ly/20yxE2n

124. Briasco B, Capra P, Mannucci B, Perugini P (2017) Stability Study of Sunscreens with Free and Encapsulated UV Filters Contained in Plastic Packaging. Pharmaceutics 9: E19. Link: https://bit.ly/2GDYNe3

125. Blüthgen N, Meili N, Chew G, Odermatt A, Fent K (2014) Accumulation and effects of the UV-filter octocrylene in adult and embryonic zebrafish (Danio rerio). Sci Total Environ 476-477: 207-217. Link: https://bit.ly/20vxfxL

126. Sung CR, Kim KB, Lee JY, Lee BM, Kwack SJ (2019) Risk Assessment of Ethylhexyl Dimethyl PABA in Cosmetics.

Abbul Kader Mohiuddin, Bangladesh

ISBN: 978-81-943057-1-2

PeertechzPublications Inc.
Toxicol Res 35: 131-136. Link: https://bit.ly/2YiOzdC

127. Draelos ZD (2008) Procedures in Cosmetic Dermatology Edition 2, published by Elsevier Health Sciences. Link: https://tinyurl.com/yxz84mzj

128. Bastien N, Millau JF, Rouabhia M, Davies RJ, Drouin R (2010) The sunscreen agent 2 phenylbenzimidazole-5sulfonic acid photosensitizes the formation of oxidized guanines in cellulo after UV-A or UV-B exposure. J Invest Dermatol 130: 2463-2471. Link: https://bit.ly/2GBrurJ

129. Inbaraj JJ, Bilski P, Chignell CF (2002) Photophysical and photochemical studies of 2-henylbenzimidazole and UVB sunscreen 2-phenylbenzimidazole-5-sulfonic acid. Photochem Photobiol 75: 107-116. Link: https://bit. ly/2uJL5Bu

130. Rai R, Shanmuga SC, Srinivas C (2012) Update on photoprotection. Indian J Dermatol 57: 335-342. Link: https://bit.ly/314Nflv

131. Rigel DS, Friedman R, Robinson JK, Ross MI, Cockerell CJ, et al. (2011) Cancer of the Skin E-Book: Expert Consult Edition 2. Elsevier Health Sciences Link: https://bit. ly/2YB12F4

132. (2006) Approved Drug Products and Legal Requirements. Thomson Micromedex, Link: https://tinyurl.com/y4xcepyy

133. USP DI (2005) Approved Drug Products and Legal Requirement. Thomson/MICROMEDEX. Link: https://bit. Iy/2YwEfKI

134. Lin EW, Boehnke N, Maynard HD (2014) Protein-polymer conjugation via ligand affinity and photoactivation of glutathione S-transferase. Bioconjug Chem 25: 19021909. Link: https://bit.ly/2K509yK

135. Hermanson GT (2013) Chapter 18 - PEGylation and Synthetic Polymer Modification. Bioconjugate Techniques (Third edition) 2013: 787-838. Link: https://tinyurl.com/ y3kfup5n

136. US FDA Database. CFR - Code of Federal Regulations Title 21 Link: https://bit.ly/2ytTyZK

137. Lowe NJ (1996) Sunscreens: Development: Evaluation, and Regulatory Aspects: Second Edition. Cosmetic science and technology series. Link: https://bit.ly/333hrpb

138. Kaur A, Thatai P, Sapra B (2014) Need of UV protection and evaluation of efficacy of sunscreens. J Cosmet Sci 65: 315-345. Link: https://bit.ly/2LSLASI

139. Trolamine salicylate. Link: https://bit.ly/333bOXT

140. Smijs TG, Pavel S (2011) Titanium dioxide and zinc oxide nanoparticles in sunscreens: focus on their safety and effectiveness. Nanotechnol Sci Appl 4: 95-112. Link: https://bit.ly/2YBK4WU

141. Trivedi M, Murase J (2017) Chapter 4: Titanium Dioxide in Sunscreen. Janus M (2017) Application of Titanium Dioxide. Intech Open. Link: https://bit.ly/2Ki1fl8

142. Mohammed YH, Holmes A, Haridass IN, Sanchez WY, Studier H, et al. (2019) Support for the Safe Use of Zinc 
Oxide Nanoparticle Sunscreens: Lack of Skin Penetration or Cellular Toxicity after Repeated Application in Volunteers. J Invest Dermatol 139: 308-315. Link: https:// bit.ly/2YjYK1N

143. Wright PFA (2019) Realistic Exposure Study Assists Risk Assessments of ZnO Nanoparticle Sunscreens and Allays Safety Concerns. J Invest Dermatol 139: 277-278. Link: https://bit.ly/2YAqsXp

144. Jiang J, Pi J, Cai J (2018) The Advancing of Zinc Oxide Nanoparticles for Biomedical Applications. Bioinorg Chem Appl 2018: 1062562. Link: https://bit.ly/2YBSsdg

145. Tian L, Lin B, Wu L, Li K, Liu H, et al. (2015) Neurotoxicity induced by zinc oxide nanoparticles: age-related differences and interaction. Sci Rep 5: 16117. Link: https://bit.ly/2ysHCrb

146. Weber C, Podda M, Rallis $M$, Thiele JJ, Traber MG, et al. (1997) Efficacy of topically applied tocopherols and tocotrienols in protection of murine skin from oxidative damage induced by UV-irradiation. Free Radic Biol Med 22: 761-769. Link: https://bit.ly/2yqi2mG

147. Iwata H, Shimada K (2012) Formulas, Ingredients and Production of Cosmetics: Technology of Skin- and HairCare Products in Japan. Springer Science \& Business Media. Link: https://bit.ly/2MurdL7

148. Rowe RC, Sheskey PJ, Quinn ME (2009) Handbook of Pharmaceutical Excipients, edition 6. Pharmaceutical Press. Link: https://bit.ly/2Mx1S31

149. Lachenmeier DW (2008) Safety evaluation of topical applications of ethanol on the skin and inside the oral cavity. J Occup Med Toxicol 3: 26. Link: https://bit. ly/2OvjKOw

150. SD Alcohol 40. Link: https://bit.ly/2SWC4ik

151. Romanowski P (2011) Cosmetic formulation basics Sunscreens. Link: https://bit.ly/2yua8J6

152. Rattanachaikunsopon P, Phumkhachorn P (2007) Bacteriostatic effect of flavonoids isolated from leaves of Psidium guajava on fish pathogens. Fitoterapia 78: 434436. Link: https://bit.ly/2GFo874

153. Morin (2019) National Center for Biotechnology Information. Pub Chem Database. Link: https://bit. ly/2SWBIh6

154. Beasley DG, Meyer TA (2010) Characterization of the UVA protection provided by avobenzone, zinc oxide, and titanium dioxide in broad-spectrum sunscreen products. Am J Clin Dermatol Link: https://bit.ly/333n6vr

155. Zirwas MJ, Andrasik W (2018) Can Sunscreens Harm Coral Reefs? Addressing Environmental Concerns and Offering Practical Recommendations. Skinmed 16: 223229. Link: https://bit.ly/2Kmjn3o

156. Belluz $J$ (2018) Hawaii is banning sunscreens that kill coral reefs. Vox. Link: https://bit.ly/2IRAxTS

157. Danovaro R, Bongiorni L, Corinaldesi C, Giovannelli D, Damiani E,et al. (2018) Sunscreens cause coral bleaching by promoting viral infections. Environ Health Perspect 116: 441-447. Link: https://bit.ly/2Kh6qYS

158. Leonardo Di Caprio Foundation. Replenishing Coral Reefs in the Pacific Ocean. Link: https://bit.ly/2YEcCDe

159. Rick D, Kellerman, David R (20118) Conn's Current Therapy 2019. Elsevier Health Sciences1031. Link: https://tinyurl. com/y6j4tjjp

160. Azevedo M, Bandeira L, Luza C, Lemos A, Bandeira F (2018) Vitamin D Deficiency, Skin Phototype, Sun Index, and Metabolic Risk Among Patients with High Rates of Sun Exposure Living in the Tropics. J Clin Aesthet Dermatol 11: 15-18. Link: https://tinyurl.com/y54opdd5

161. Scott JF, Das LM, Ahsanuddin S, Qiu Y, Binko AM, et al. (2017) Oral Vitamin D Rapidly Attenuates Inflammation from Sunburn: An Interventional Study. J Invest Dermatol Link: https://tinyurl.com/y3fpa4t3

162. Schalka S, Steiner D, Ravelli FN, Steiner T, Terena AC, et al. (2014) Brazilian consensus on photoprotection. An Bras Dermatol 89: 1-74. Link: https://tinyurl.com/y63d3qw6

163. Web WHO. Ultraviolet radiation (UV). Link: https://tinyurl. com/y6jc3x98

164. Engelsen $O$ (2010) The relationship between ultraviolet radiation exposure and vitamin D status. 2: 482-495. Link: https://tinyurl.com/y2byymf5

165. Diffey BL (2002) Human exposure to solar ultraviolet radiation. J Cosmet Dermatol 1: 124-130. Link: https:// tinyurl.com/yxz5ur63

166. Govindu PCV, Hosamani B, Moi S, Venkatachalam D, Asha S, et al. (2019) Glutathione as a photo-stabilizer of avobenzone: an evaluation under glass-filtered sunlight using UV-spectroscopy. Photochem Photobiol Sci 18: 198-207. Link: https://tinyurl.com/y6jonndd

167. Wang J, Pan L, Wu S, Lu L, Xu Y, et al. (2016) Recent Advances on Endocrine Disrupting Effects of UV Filters. Int J Environ Res Public Health 13: E782. Link: https:// tinyurl.com/y6mbfhms

168.(2019) Trolamine salicylate. National Center for Biotechnology Information. Pub Chem Database. Link: https://tinyurl.com/y2xp9nbj

169. Schwarz T (2005) Mechanisms of UV-induced immunosuppression. Keio J Med 54: 165-171. Link: https://bit.ly/2KdOKis

170. Ullrich SE (2005) Mechanisms underlying UV-induced immune suppression. Mutat Res 571: 185-205. Link: https://bit.ly/2LW7vbx

171. Katiyar SK (2007) UV-induced immune suppression and photocarcinogenesis: chemoprevention by dietary botanical agents. Cancer Lett 255: 1-11. Link: https://bit. ly/20xnRcM

172. Fisher GJ, Kang S, Varani J, Bata-Csorgo Z, Wan Y, et al. (2002) Mechanisms of Photoaging and Chronological Skin Aging. Arch Dermatol 138: 1462-1470. Link: https:// bit.ly/2GCYIHy

Abdul Kader Mohiuddin, Bangladesh ISBN: 978-81-943057-1-2 doi: https://dx.doi.org/10.17352/ebook10112 
173. Rabe JH, Mamelak AJ, McElgunn PJ, Morison WL, Sauder DN (2006) Photoaging: mechanisms and repair. J Am Acad Dermatol 55: 1-19. Link: https://bit.ly/2KkntZS

174. Rittié L, Fisher GJ (2015) Natural and sun-induced aging of human skin. Cold Spring Harb Perspect Med 5: a015370. Link: https://bit.ly/2YjNsKP

175. Amano S (2016) Characterization and mechanisms of photoageing-related changes in skin. Damages of basement membrane and dermal structures. Exp Dermatol 3: 14-19. Link: https://bit.ly/2yujYum

176. Pamela RD (2018) Topical Growth Factors for the Treatment of Facial Photoaging: A Clinical Experience of Eight Cases. J Clin Aesthet Dermatol 11: 28-29. Link: https://bit.ly/2ONtGTV

177. Tanner PR (2006) Sunscreen product formulation. Dermatol Clin 24: 53-62. Link: https://bit.ly/2YzLOix

178. Habbema L, Halk AB, Neumann M, Bergman W (2017) Risks of unregulated use of alpha-melanocyte-stimulating hormone analogues: a review. Int J Dermatol 56: 975-980. Link: https://bit.ly/316PtXF

179. Garone M, Howard J, Fabrikant J (2015) A review of common tanning methods. J Clin Aesthet Dermatol 8: 4347. Link: https://bit.ly/2LThU89

180. Ciriminna R, Fidalgo A, Ilharco LM, Pagliaro M (2018) Dihydroxyacetone: An Updated Insight into an Important Bioproduct. Chemistry Open 7: 233-236. Link: https://bit. ly/2LUluhe

181. Martini MC (2017) [Self-tanning and sunless tanning products]. Ann Dermatol Venereol 144: 638-644. Link: https://bit.ly/317aUbe

182. (2018) Give me a tan! - Megan Fox. News24.com Link: https://bit.ly/2Msqavf

183. March B (2014) 10 celebs who look better tan-free. COSMOPOLITAN. Link: https://bit.ly/2YzkSAD

184. Haggan M (2018) Warning on incorrect sunscreen use. Australian Journal of Pharmacy. Link: https://bit. ly/2mD39XT

185. Reef-safe Sunscreen: What You Need to Know. Blog CHASING CORAL. Link: https://bit.ly/2MNXIRO
Discover a bigger Impact and Visibility of your article publication with

\section{Peertechz Publications}

\section{Highlights}

* Signatory publisher of ORCID

* Signatory Publisher of DORA (San Francisco Declaration on Research Assessment)

* Articles archived in worlds' renowned service providers such as Portico, CNKI, AGRIS, TDNet, Base (Bielefeld University Library), CrossRef, Scilit, J-Gate etc.

* Journals indexed in ICMJE, SHERPA/ROMEO, Google Scholar etc.

* OAI-PMH (Open Archives Initiative Protocol for Metadata Harvesting)

* Dedicated Editorial Board for every journal

* Accurate and rapid peer-review process

* Increased citations of published articles through promotions

* Reduced timeline for article publication

Submit your articles and experience a new surge in publication services (https://www.peertechz.com/submission).

Peertechz journals wishes everlasting success in your every endeavours 
